\title{
Applications of Bregman-Opial Property to Bregman Nonspreading Mappings in Banach Spaces
}

\author{
Eskandar Naraghirad, ${ }^{1}$ Ngai-Ching Wong, ${ }^{2}$ and Jen-Chih Yao ${ }^{3}$ \\ ${ }^{1}$ Department of Mathematics, Yasouj University, Yasouj 75918, Iran \\ ${ }^{2}$ Department of Applied Mathematics, National Sun Yat-sen University, Kaohsiung 804, Taiwan \\ ${ }^{3}$ Center for General Education, Kaohsiung Medical University, Kaohsiung 807, Taiwan
}

Correspondence should be addressed to Eskandar Naraghirad; eskandarrad@gmail.com

Received 29 October 2013; Accepted 6 December 2013; Published 16 January 2014

Academic Editor: Jinlu Li

Copyright (C) 2014 Eskandar Naraghirad et al. This is an open access article distributed under the Creative Commons Attribution License, which permits unrestricted use, distribution, and reproduction in any medium, provided the original work is properly cited.

The Opial property of Hilbert spaces and some other special Banach spaces is a powerful tool in establishing fixed point theorems for nonexpansive and, more generally, nonspreading mappings. Unfortunately, not every Banach space shares the Opial property. However, every Banach space has a similar Bregman-Opial property for Bregman distances. In this paper, using Bregman distances, we introduce the classes of Bregman nonspreading mappings and investigate the Mann and Ishikawa iterations for these mappings. We establish weak and strong convergence theorems for Bregman nonspreading mappings.

\section{Introduction}

Let $E$ be a (real) Banach space with norm $\|\cdot\|$ and dual space $E^{*}$. For any $x$ in $E$, we denote the value of $x^{*}$ in $E^{*}$ at $x$ by $\left\langle x, x^{*}\right\rangle$. When $\left\{x_{n}\right\}_{n \in \mathbb{N}}$ is a sequence in $E$, we denote the strong convergence of $\left\{x_{n}\right\}_{n \in \mathbb{N}}$ to $x \in E$ by $x_{n} \rightarrow x$ and the weak convergence by $x_{n} \rightarrow x$. Let $C$ be a nonempty subset of $E$. Let $T: C \rightarrow E$ be a map. We denote by $F(T)=\{x \in C$ : $T x=x\}$ the set of fixed points of $T$. We call the map $T$

(i) nonexpansive if $\|T x-T y\| \leq\|x-y\|$ for all $x, y$ in $C$,

(ii) quasi-nonexpansive if $F(T) \neq \emptyset$ and $\|T x-y\| \leq\|x-y\|$ for all $x$ in $C$ and $y$ in $F(T)$.

The nonexpansivity plays an important role in the study of the Ishikawa iteration, given by

$$
\begin{aligned}
y_{n} & =\beta_{n} T x_{n}+\left(1-\beta_{n}\right) x_{n}, \\
x_{n+1} & =\gamma_{n} T y_{n}+\left(1-\gamma_{n}\right) x_{n},
\end{aligned}
$$

where the sequences $\left\{\beta_{n}\right\}_{n \in \mathbb{N}}$ and $\left\{\gamma_{n}\right\}_{n \in \mathbb{N}}$ satisfy some appropriate conditions. When all $\beta_{n}=0$, Ishikawa iteration (1) reduces to the classical Mann iteration. Construction of fixed points of nonexpansive mappings via Mann's and
Ishikawa's algorithms [1] has been extensively investigated in the literature (see, e.g., [2] and the references therein).

A powerful tool in deriving weak or strong convergence of iterative sequences is due to Opial [3]. A Banach space $E$ is said to satisfy the Opial property [3] if for any weakly convergent sequence $\left\{x_{n}\right\}_{n \in \mathbb{N}}$ in $E$ with weak limit $x$ we have

$$
\limsup _{n \rightarrow \infty}\left\|x_{n}-x\right\|<\limsup _{n \rightarrow \infty}\left\|x_{n}-y\right\|,
$$

for all $y$ in $E$ with $y \neq x$. It is well known that all Hilbert spaces, all finite dimensional Banach spaces, and the Banach spaces $l^{p}(1 \leq p<\infty)$ satisfy the Opial property. However, not every Banach space satisfies the Opial property; see, for example, $[4,5]$.

Working with the Bregman distance $D_{g}$, the following Bregman-Opial-like inequality holds for every Banach space E:

$$
\limsup _{n \rightarrow \infty} D_{g}\left(x_{n}, x\right)<\limsup _{n \rightarrow \infty} D_{g}\left(x_{n}, y\right),
$$

whenever $x_{n} \rightarrow x \neq y$. See Lemma 11 for details. The Bregman-Opial property suggests introducing the notions of Bregman nonexpansive-like mappings and developing fixed 
point theorems and convergence results for the Ishikawa iterations for these mappings.

We recall the definition of Bregman distances. Let $g$ : $E \rightarrow \mathbb{R}$ be a strictly convex and Gâteaux differentiable function on a Banach space $E$. The Bregman distance [6] (see also $[7,8])$ corresponding to $g$ is the function $D_{g}: E \times E \rightarrow \mathbb{R}$ defined by

$$
\begin{array}{r}
D_{g}(x, y)=g(x)-g(y)-\langle x-y, \nabla g(y)\rangle, \\
\forall x, y \in E .
\end{array}
$$

It follows from the strict convexity of $g$ that $D_{g}(x, y) \geq 0$ for all $x, y$ in $E$. However, $D_{g}$ might not be symmetric and $D_{g}$ might not satisfy the triangular inequality.

When $E$ is a smooth Banach space, setting $g(x)=\|x\|^{2}$ for all $x$ in $E$, we have that $\nabla g(x)=2 J x$ for all $x$ in $E$. Here $J$ is the normalized duality mapping from $E$ into $E^{*}$. Hence, $D_{g}(\cdot, \cdot)$ reduces to the usual map $\phi(\cdot, \cdot)$ as

$$
\begin{array}{r}
D_{g}(x, y)=\phi(x, y):=\|x\|^{2}-2\langle x, J y\rangle+\|y\|^{2}, \\
\forall x, y \in E .
\end{array}
$$

If $E$ is a Hilbert space, then $D_{g}(x, y)=\|x-y\|^{2}$.

Let $g: E \rightarrow \mathbb{R}$ be strictly convex and Gâteaux differentiable, and let $C \subseteq E$ be nonempty. A mapping $T$ : $C \rightarrow E$ is said to be

(i) Bregman nonexpansive if

$$
D_{g}(T x, T y) \leq D_{g}(x, y), \quad \forall x, y \in C ;
$$

(ii) Bregman quasi-nonexpansive if $F(T) \neq \emptyset$ and

$$
D_{g}(p, T x) \leq D_{g}(p, x), \quad \forall x \in C, \forall p \in F(T) ;
$$

(iii) Bregman skew quasi-nonexpansive if $F(T) \neq \emptyset$ and

$$
D_{g}(T x, p) \leq D_{g}(x, p), \quad \forall x \in C, \forall p \in F(T),
$$

(iv) Bregman nonspreading if

$$
\begin{aligned}
& D_{g}(T x, T y)+D_{g}(T y, T x) \\
& \quad \leq D_{g}(T x, y)+D_{g}(T y, x), \quad \forall x, y \in C .
\end{aligned}
$$

It is obvious that every Bregman nonspreading map $T$ with $F(T) \neq \emptyset$ is Bregman quasi-nonexpansive. Bregman nonspreading mappings include, in particular, the class of nonspreading functions studied by Takahashi and his coauthors (see, e.g., $[9,10]$ ), which is defined with the map $\phi$ in (5).

Let us give an example of a Bregman nonspreading mapping with nonempty fixed point set, which is not quasinonexpansive.

Example 1. Let $g: \mathbb{R} \rightarrow \mathbb{R}$ be defined by $g(x)=x^{4}$. The associated Bregman distance is given by

$$
\begin{aligned}
D_{g}(x, y) & =x^{4}-y^{4}-4(x-y) y^{3} \\
& =x^{4}+3 y^{4}-4 x y^{3}, \quad \forall x, y \in R .
\end{aligned}
$$

Define $T:[0,2] \rightarrow[0,2]$ by

$$
T x=\left\{\begin{array}{lc}
0 & \text { if } x \in[0,2), \\
1 & \text { if } x=2 .
\end{array}\right.
$$

We have $F(T)=\{0\}$. Plainly, $T$ is neither nonexpansive nor continuous.

However, $T$ is Bregman nonspreading. To see this, we define $f:[0,2] \times[0,2] \rightarrow \mathbb{R}$ by

$$
\begin{aligned}
f(x, y)= & D_{g}(T x, T y)+D_{g}(T y, T x) \\
& -D_{g}(T x, y)-D_{g}(T y, x), \quad \forall x, y \in[0,2] .
\end{aligned}
$$

Consider the following three possible cases.

Case 1. If $x=y=2$, then we have $T x=T y=1$ and hence

$$
f(2,2)=0+0-17-17=-34<0 .
$$

Case 2. If $x=2$ and $y \in[0,2)$, then we have $T x=1, T y=0$, and hence

$$
\begin{aligned}
f(2, y) & =1+3-1-3 y^{4}+4 y^{3}-48 \\
& =-3 y^{4}+4 y^{3}-45<0 .
\end{aligned}
$$

Case 3. If $x, y \in[0,2)$, then we have $T x=T y=0$ and hence

$$
f(x, y)=-3\left(x^{4}+y^{4}\right) \leq 0 .
$$

Thus we have $f(x, y) \leq 0$ for all $x, y$ in $[0,2]$ and hence $T$ is a Bregman nonspreading mapping.

In Section 2, we collect and study some basic ties of Bregman distances. In Section 3, utilizing the Bregman-Opial property, we present some fixed point theorems. In Sections 4 and 5, we investigate weak and strong convergence of the Ishikawa and Bregman-Ishikawa iterations for Bregman nonspreading mappings. Our results improve and generalize some known results in the current literature; see, for example, [11].

\section{Bregman Functions and Bregman Distances}

Let $E$ be a (real) Banach space, and let $g: E \rightarrow \mathbb{R}$. For any $x$ in $E$, the gradient $\nabla g(x)$ is defined to be the linear functional in $E^{*}$ such that

$$
\langle y, \nabla g(x)\rangle=\lim _{t \rightarrow 0} \frac{g(x+t y)-g(x)}{t}, \quad \forall y \in E .
$$

The function $g$ is said to be Gâteaux differentiable at $x$ if $\nabla g(x)$ is well defined, and $g$ is Gâteaux differentiable if it is Gâteaux differentiable everywhere on $E$. We call $g$ Fréchet differentiable at $x$ (see, e.g., [12, page 13] or [13, page 508]) if, for all $\epsilon>0$, there exists $\delta>0$ such that

$$
\begin{array}{r}
|g(y)-g(x)-\langle y-x, \nabla g(x)\rangle| \leq \epsilon\|y-x\|, \\
\text { whenever }\|y-x\| \leq \delta .
\end{array}
$$


The function $g$ is said to be Fréchet differentiable if it is Fréchet differentiable everywhere.

Let $B$ be the closed unit ball of a Banach space $E$. A function $g: E \rightarrow \mathbb{R}$ is said to be

(i) strongly coercive if

$$
\lim _{\left\|x_{n}\right\| \rightarrow+\infty} \frac{g\left(x_{n}\right)}{\left\|x_{n}\right\|}=+\infty ;
$$

(ii) locally bounded if $g(r B)$ is bounded for all $r>0$;

(iii) locally uniformly smooth on $E$ ([14, pp. 207, 221]) if the function $\sigma_{r}:[0,+\infty) \rightarrow[0,+\infty]$, defined by

$$
\begin{aligned}
& \sigma_{r}(t) \\
& =\sup _{x \in r B, y \in S_{E}, \alpha \in(0,1)}(\alpha g(x+(1-\alpha) t y) \\
& +(1-\alpha) g(x-\alpha t y)-g(x)) \\
& \times(\alpha(1-\alpha))^{-1 / 2},
\end{aligned}
$$

satisfies

$$
\lim _{t \downarrow 0} \frac{\sigma_{r}(t)}{t}=0, \quad \forall r>0 ;
$$

(iv) locally uniformly convex on $E$ (or uniformly convex on bounded subsets of $E([14$, pp. 203, 221])) if the gauge $\rho_{r}:[0,+\infty) \rightarrow[0,+\infty]$ of uniform convexity of $g$, defined by

$\rho_{r}(t)$

$$
\begin{gathered}
=\inf _{x, y \in r B,\|x-y\|=t, \alpha \in(0,1)}(\alpha g(x)+(1-\alpha) g(y) \\
-g(\alpha x+(1-\alpha) y)) \\
\quad \times(\alpha(1-\alpha))^{-1 / 2},
\end{gathered}
$$

satisfies

$$
\rho_{r}(t)>0, \quad \forall r, t>0 .
$$

For a locally uniformly convex map $g: E \rightarrow \mathbb{R}$, we have

$$
\begin{aligned}
g(\alpha x+(1-\alpha) y) \leq & \alpha(x) g+(1-\alpha) g(y) \\
& -\alpha(1-\alpha) \rho_{r}(\|x-y\|),
\end{aligned}
$$

for all $x, y$ in $r B$ and for all $\alpha$ in $(0,1)$.

Let $E$ be a Banach space and $g: E \rightarrow \mathbb{R}$ a strictly convex and Gâteaux differentiable function. By (4), the Bregman distance satisfies that [6]

$$
\begin{aligned}
D_{g}(x, z)= & D_{g}(x, y)+D_{g}(y, z) \\
& +\langle x-y, \nabla g(y)-\nabla g(z)\rangle, \quad \forall x, y, z \in E .
\end{aligned}
$$

In particular,

$$
\begin{aligned}
D_{g}(x, y)= & -D_{g}(y, x) \\
& +\langle y-x, \nabla g(y)-\nabla g(x)\rangle, \quad \forall x, y \in E .
\end{aligned}
$$

Lemma 2 (see [15]). Let $E$ be a Banach space and $g: E \rightarrow$ $\mathbb{R}$ a Gâteaux differentiable function which is locally uniformly convex on $E$. Let $\left\{x_{n}\right\}_{n \in \mathbb{N}}$ and $\left\{y_{n}\right\}_{n \in \mathbb{N}}$ be bounded sequences in $E$. Then the following assertions are equivalent:

(1) $\lim _{n \rightarrow \infty} D_{g}\left(x_{n}, y_{n}\right)=0$,

(2) $\lim _{n \rightarrow \infty}\left\|x_{n}-y_{n}\right\|=0$.

The following Bregman-Opial-like inequality has been proved in [16].

Lemma 3 (see [16]). Let $E$ be a Banach space and let $g: E \rightarrow$ $\mathbb{R}$ be a strictly convex and Gâteaux differentiable function. Suppose $\left\{x_{n}\right\}_{n \in \mathbb{N}}$ is a sequence in E such that $x_{n} \rightarrow x$ for some $x$ in $E$. Then

$$
\limsup _{n \rightarrow \infty} D_{g}\left(x_{n}, x\right)<\limsup _{n \rightarrow \infty} D_{g}\left(x_{n}, y\right),
$$

for all $y$ in the interior of dom $g$ with $y \neq x$.

We call a function $g: E \rightarrow(-\infty,+\infty]$ lower semicontinuous if $\{x \in E: g(x) \leq r\}$ is closed for all $r$ in $\mathbb{R}$. For a lower semicontinuous convex function $g: E \rightarrow \mathbb{R}$, the subdifferential $\partial g$ of $g$ is defined by

$$
\begin{aligned}
\partial g(x)=\left\{x^{*} \in E^{*}: g(x)\right. \\
\left.\quad+\left\langle y-x, x^{*}\right\rangle \leq g(y), \forall y \in E\right\},
\end{aligned}
$$

for all $x$ in $E$. It is well known that $\partial g \subset E \times E^{*}$ is maximal monotone $[17,18]$. For any lower semicontinuous convex function $g: E \rightarrow(-\infty,+\infty]$, the conjugate function $g^{*}$ of $g$ is defined by

$$
g^{*}\left(x^{*}\right)=\sup _{x \in E}\left\{\left\langle x, x^{*}\right\rangle-g(x)\right\}, \quad \forall x^{*} \in E^{*} .
$$

It is well known that

$$
\begin{gathered}
g(x)+g^{*}\left(x^{*}\right) \geq\left\langle x, x^{*}\right\rangle, \quad \forall\left(x, x^{*}\right) \in E \times E^{*}, \\
\left(x, x^{*}\right) \in \partial g \text { is equivalent to } g(x)+g^{*}\left(x^{*}\right)=\left\langle x, x^{*}\right\rangle .
\end{gathered}
$$

We also know that if $g: E \rightarrow(-\infty,+\infty]$ is a proper lower semicontinuous convex function, then $g^{*}: E^{*} \rightarrow$ $(-\infty,+\infty]$ is a proper weak ${ }^{*}$ lower semicontinuous convex function. Here, saying $g$ is proper we mean that dom $g:=$ $\{x \in E: g(x)<+\infty\} \neq \emptyset$.

The following definition is slightly different from that in Butnariu and Iusem [12].

Definition 4 (see [13]). Let $E$ be a Banach space. A function $g: E \rightarrow \mathbb{R}$ is said to be a Bregman function if the following conditions are satisfied:

(1) $g$ is continuous, strictly convex, and Gâteaux differentiable;

(2) the set $\left\{y \in E: D_{g}(x, y) \leq r\right\}$ is bounded for all $x$ in $E$ and $r>0$. 
The following lemma follows from Butnariu and Iusem [12] and Zǎlinescu [14].

Lemma 5. Let $E$ be a reflexive Banach space and $g: E \rightarrow \mathbb{R}$ a strongly coercive Bregman function. Then

(1) $\nabla g: E \rightarrow E^{*}$ is one-to-one, onto, and norm-to-weak ${ }^{*}$ continuous;

(2) $\langle x-y, \nabla g(x)-\nabla g(y)\rangle=0$ if and only if $x=y$;

(3) $\left\{x \in E: D_{g}(x, y) \leq r\right\}$ is bounded for all $y$ in $E$ and $r>0$

(4) dom $g^{*}=E^{*}, g^{*}$ is Gâteaux differentiable, and $\nabla g^{*}=$ $(\nabla g)^{-1}$. 3.6.4].

The following two results follow from [14, Proposition

Proposition 6. Let $E$ be a reflexive Banach space and let $g$ : $E \rightarrow \mathbb{R}$ be a convex function which is locally bounded. The following assertions are equivalent:

(1) $g$ is strongly coercive and locally uniformly convex on E;

(2) dom $g^{*}=E^{*}$ and $g^{*}$ is locally bounded and locally uniformly smooth on $E$;

(3) dom $g^{*}=E^{*}, g^{*}$ is Fréchet differentiable, and $\nabla g^{*}$ is uniformly norm-to-norm continuous on bounded subsets of $E^{*}$.

Proposition 7. Let $E$ be a reflexive Banach space and $g: E \rightarrow$ $\mathbb{R}$ a continuous convex function which is strongly coercive. The following assertions are equivalent:

(1) $g$ is locally bounded and locally uniformly smooth on E;

(2) $g^{*}$ is Fréchet differentiable and $\nabla g^{*}$ is uniformly normto-norm continuous on bounded subsets of E;

(3) dom $g^{*}=E^{*}$ and $g^{*}$ is strongly coercive and locally uniformly convex on $E$.

Lemma 8 (see $[13,19]$ ). Let $E$ be a reflexive Banach space, $g: E \rightarrow \mathbb{R}$ a strongly coercive Bregman function, and $V$ the function defined by

$$
V\left(x, x^{*}\right)=g(x)-\left\langle x, x^{*}\right\rangle+g^{*}\left(x^{*}\right), \quad \forall x \in E, \forall x^{*} \in E^{*} .
$$

The following assertions hold:

(1) $D_{g}\left(x, \nabla g^{*}\left(x^{*}\right)\right)=V\left(x, x^{*}\right)$ for all $x$ in $E$ and $x^{*}$ in $E^{*}$,

(2) $V\left(x, x^{*}\right)+\left\langle\nabla g^{*}\left(x^{*}\right)-x, y^{*}\right\rangle \leq V\left(x, x^{*}+y^{*}\right)$ for all $x$ in $E$ and $x^{*}, y^{*}$ in $E^{*}$.

It also follows from the definition that $V$ is convex in the second variable $x^{*}$, and

$$
V(x, \nabla g(y))=D_{g}(x, y) .
$$

Let $E$ be a Banach space and let $C$ be a nonempty convex subset of $E$. Let $g: E \rightarrow \mathbb{R}$ be a strictly convex and Gâteaux differentiable function. Then, we know from [20] that, for $x$ in $E$ and $x_{0}$ in $C$, we have

$$
\begin{aligned}
& D_{g}\left(x_{0}, x\right)=\min _{y \in C} D_{g}(y, x) \text { if and only if } \\
& \left\langle y-x_{0}, \nabla g(x)-\nabla g\left(x_{0}\right)\right\rangle \leq 0, \quad \forall y \in C .
\end{aligned}
$$

Further, if $C$ is a nonempty, closed, and convex subset of a reflexive Banach space $E$ and $g: E \rightarrow \mathbb{R}$ is a strongly coercive Bregman function, then, for each $x$ in $E$, there exists a unique $x_{0}$ in $C$ such that

$$
D_{g}\left(x_{0}, x\right)=\min _{y \in C} D_{g}(y, x) \text {. }
$$

The Bregman projection proj ${ }_{C}^{g}$ from $E$ onto $C$ defined by $\operatorname{proj}_{C}^{g}(x)=x_{0}$ has the following property:

$$
\begin{aligned}
& D_{g}\left(y, \operatorname{proj}_{C}^{g} x\right)+D_{g}\left(\operatorname{proj}_{C}^{g} x, x\right) \\
& \quad \leq D_{g}(y, x), \quad \forall y \in C, \forall x \in E .
\end{aligned}
$$

See [12] for details.

Let $E$ be a reflexive Banach space and let $g: E \rightarrow$ $\mathbb{R}$ be a lower semicontinuous, strictly convex, and Gâteaux differentiable function. Let $C$ be a nonempty, closed, and convex subset of $E$ and let $\left\{x_{n}\right\}_{n \in \mathbb{N}}$ be a bounded sequence in $E$. For any $x$ in $E$, we set

$$
\operatorname{Br}\left(x,\left\{x_{n}\right\}\right)=\limsup _{n \rightarrow \infty} D_{g}\left(x_{n}, x\right) .
$$

The Bregman asymptotic radius of $\left\{x_{n}\right\}_{n \in \mathbb{N}}$ relative to $C$ is defined by

$$
\operatorname{Br}\left(C,\left\{x_{n}\right\}\right)=\inf \left\{\operatorname{Br}\left(x,\left\{x_{n}\right\}\right): x \in C\right\} .
$$

The Bregman asymptotic center of $\left\{x_{n}\right\}_{n \in \mathbb{N}}$ relative to $C$ is the set

$$
\operatorname{BA}\left(C,\left\{x_{n}\right\}\right)=\left\{x \in C: \operatorname{Br}\left(x,\left\{x_{n}\right\}\right)=\operatorname{Br}\left(C,\left\{x_{n}\right\}\right)\right\} .
$$

Proposition 9. Let $C$ be a nonempty, closed, and convex subset of a reflexive Banach space $E$, and let $g: E \rightarrow \mathbb{R}$ be strictly convex, Gâteaux differentiable, and locally bounded on E. If $\left\{x_{n}\right\}_{n \in \mathbb{N}}$ is a bounded sequence of $C$, then $B A\left(C,\left\{x_{n}\right\}_{n \in \mathbb{N}}\right)$ is a singleton.

Proof. In view of the definition of Bregman asymptotic radius, we may assume that $\left\{x_{n}\right\}_{n \in \mathbb{N}}$ converges weakly to $z$ in C. By Lemma 3, we conclude that $\operatorname{BA}\left(C,\left\{x_{n}\right\}_{n \in \mathbb{N}}\right)=\{z\}$.

\section{Fixed Point Theorems}

Lemma 10 (see [21]). Let $C$ be a nonempty, closed, and convex subset of a reflexive Banach space $E$. Let $g: E \rightarrow \mathbb{R}$ be strictly convex, continuous, strongly coercive, Gâteaux differentiable, and locally bounded on $E$. Let $T: C \rightarrow E$ be a Bregman quasinonexpansive mapping. Then $F(T)$ is closed and convex. 
Lemma 11. Let $C$ be a nonempty, closed, and convex subset of a reflexive Banach space $E$. Let $g: E \rightarrow \mathbb{R}$ be a strictly convex and Gâteaux differentiable function. Let $T: C \rightarrow E$ be a Bregman nonspreading mapping. Then

$$
\begin{aligned}
& D_{g}(x, T y) \leq D_{g}(x, y)+D_{g}(T x, x) \\
&+\langle x-T x, \nabla g(y)-\nabla g(T y)\rangle \\
&+\langle T x-T y, \nabla g(x)-\nabla g(T x)\rangle, \\
& \forall x, y \in C .
\end{aligned}
$$

Proof. Let $x, y \in C$. In view of (24), we have

$$
\begin{aligned}
D_{g}(T x, T y) \leq & D_{g}(T x, y)+D_{g}(T y, x)-D_{g}(T y, T x) \\
= & D_{g}(T x, x)+D_{g}(x, y) \\
& +\langle T x-x, \nabla g(x)-\nabla g(y)\rangle \\
& +D_{g}(T y, T x)+D_{g}(T x, x) \\
& +\langle T y-T x, \nabla g(T x)-\nabla g(x)\rangle-D_{g}(T y, T x) \\
= & D_{g}(x, y)+2 D_{g}(T x, x) \\
& +\langle T x-x, \nabla g(x)-\nabla g(y)\rangle \\
& +\langle T x-T y, \nabla g(x)-\nabla g(T x)\rangle .
\end{aligned}
$$

This, together with (24), implies that

$$
\begin{aligned}
D_{g}(x, T y)= & D_{g}(x, T x)+D_{g}(T x, T y) \\
& +\langle x-T x, \nabla g(T x)-\nabla g(T y)\rangle \\
\leq & D_{g}(x, T x)+D_{g}(x, y)+2 D_{g}(T x, x) \\
& +\langle T x-x, \nabla g(x)-\nabla g(y)\rangle \\
& +\langle T x-T y, \nabla g(x)-\nabla g(T x)\rangle \\
& +\langle x-T x, \nabla g(T x)-\nabla g(T y)\rangle \\
= & D_{g}(x, y)+D_{g}(T x, x) \\
& +\langle x-T x, \nabla g(x)-\nabla g(T x)\rangle \\
& +\langle T x-T y, \nabla g(x)-\nabla g(T x)\rangle \\
& +\langle T x-x, \nabla g(x)-\nabla g(y)\rangle \\
& +\langle x-T x, \nabla g(T x)-\nabla g(T y)\rangle \\
= & D_{g}(x, y)+D_{g}(T x, x) \\
& +\langle x-T x, \nabla g(y)-\nabla g(T y)\rangle \\
& +\langle T x-T y, \nabla g(x)-\nabla g(T x)\rangle .
\end{aligned}
$$

Proposition 12 (demiclosedness principle). Let $C$ be a nonempty subset of a reflexive Banach space E. Let $g: E \rightarrow$ $\mathbb{R}$ be a strictly convex, Gâteaux differentiable, and locally bounded function. Let $T: C \rightarrow$ E be a Bregman nonspreading mapping. If $x_{n} \rightarrow z$ in $C$ and $\lim _{n \rightarrow \infty}\left\|T x_{n}-x_{n}\right\|=0$, then $T z=z$. That is, $I-T$ is demiclosed at zero, where $I$ is the identity mapping on $E$.

Proof. Since $\left\{x_{n}\right\}_{n \in \mathbb{N}}$ converges weakly to $z$ and $\lim _{n \rightarrow \infty}\left\|T x_{n}-x_{n}\right\|=0$, both the sequences $\left\{x_{n}\right\}_{n \in \mathbb{N}}$ and $\left\{T x_{n}\right\}_{n \in \mathbb{N}}$ are bounded. Since $\nabla g$ is uniformly norm-tonorm continuous on bounded subsets of $E$ (see, e.g., [14]), we arrive at

$$
\lim _{n \rightarrow \infty}\left\|\nabla g\left(x_{n}\right)-\nabla g\left(T x_{n}\right)\right\|=0 .
$$

In view of Lemma 2 , we deduce that $\lim _{n \rightarrow \infty} D_{g}\left(x_{n}, T x_{n}\right)=$ 0 . Set

$$
\begin{aligned}
M_{1} & =\sup \left\{\left\|T x_{n}\right\|,\|T z\|,\|\nabla g(z)\|,\|\nabla g(T z)\|: n \in \mathbb{N}\right\} \\
& <+\infty .
\end{aligned}
$$

By Lemma 11, for all $n$ in $\mathbb{N}$,

$$
\begin{aligned}
D_{g}( & \left.x_{n}, T z\right) \\
\leq & D_{g}\left(x_{n}, z\right)+D_{g}\left(T x_{n}, x_{n}\right) \\
& +\left\langle x_{n}-T x_{n}, \nabla g(z)-\nabla g(T z)\right\rangle \\
& +\left\langle T x_{n}-T z, \nabla g\left(x_{n}\right)-\nabla g\left(T x_{n}\right)\right\rangle \\
\leq & D_{g}\left(x_{n}, z\right)+D_{g}\left(T x_{n}, x_{n}\right) \\
& +\left\|x_{n}-T x_{n}\right\|\|\nabla g(z)-\nabla g(T z)\| \\
& +\left\|T x_{n}-T z\right\|\left\|\nabla g\left(x_{n}\right)-\nabla g\left(T x_{n}\right)\right\| \\
\leq & D_{g}\left(x_{n}, z\right)+D_{g}\left(T x_{n}, x_{n}\right) \\
& +2 M_{1}\left\|x_{n}-T x_{n}\right\|+2 M_{1}\left\|\nabla g\left(x_{n}\right)-\nabla g\left(T x_{n}\right)\right\| .
\end{aligned}
$$

This implies

$$
\limsup _{n \rightarrow \infty} D_{g}\left(x_{n}, T z\right) \leq \limsup _{n \rightarrow \infty} D_{g}\left(x_{n}, z\right) .
$$

From the Bregman-Opial-like property, we obtain $T z=z$.

Let $\ell^{\infty}$ be the Banach lattice of bounded real sequences with the supremum norm. It is well known that there exists a bounded linear functional $\mu$ on $\ell^{\infty}$ such that the following three conditions hold:

(1) if $\left\{t_{n}\right\}_{n \in \mathbb{N}} \in \ell^{\infty}$ and $t_{n} \geq 0$ for every $n$ in $\mathbb{N}$, then $\mu\left(\left\{t_{n}\right\}\right) \geq 0$

(2) if $t_{n}=1$ for every $n$ in $\mathbb{N}$, then $\mu\left(\left\{t_{n}\right\}\right)=1$;

(3) $\mu\left(\left\{t_{n+1}\right\}\right)=\mu\left(\left\{t_{n}\right\}\right)$ for all $\left\{t_{n}\right\}_{n \in \mathbb{N}}$ in $\ell^{\infty}$. 
Here, $\left\{t_{n+1}\right\}$ denotes the sequence $\left(t_{2}, t_{3}, t_{4}, \ldots, t_{n+1}, \ldots\right)$ in $\ell^{\infty}$. Such a functional $\mu$ is called a Banach limit and the value of $\mu$ at $\left\{t_{n}\right\}_{n \in \mathbb{N}}$ in $\ell^{\infty}$ is denoted by $\mu_{n} t_{n}$. Therefore, condition (3) means $\mu_{n} t_{n}=\mu_{n} t_{n+1}$. If $\mu$ satisfies conditions (1) and (2), we call $\mu$ a mean on $\ell^{\infty}$. See, for example, [22].

To see some examples of those mappings $T$ satisfying all the stated hypotheses in the following result, we refer the reader to [23].

Theorem 13 (see [23]). Let $C$ be a nonempty, closed, and convex subset of a reflexive Banach space E. Let $g: E \rightarrow$ $\mathbb{R}$ be strictly convex, continuous, strongly coercive, Gâteaux differentiable, locally bounded and locally uniformly convex on E. Let $T: C \rightarrow C$ be a mapping. Let $\left\{x_{n}\right\}_{n \in \mathbb{N}}$ be a bounded sequence of $C$ and let $\mu$ be a mean on $\ell^{\infty}$. Suppose that

$$
\mu_{n} D_{g}\left(x_{n}, T y\right) \leq \mu_{n} D_{g}\left(x_{n}, y\right), \quad \forall y \in C .
$$

Then $T$ has a fixed point in $C$.

Corollary 14. Let $C$ be a nonempty, bounded, closed, and convex subset of a reflexive Banach space E. Let $g: E \rightarrow$ $\mathbb{R}$ be strictly convex, continuous, strongly coercive, Gâteaux differentiable function, locally bounded, and locally uniformly convex on $E$. Let $T: C \rightarrow C$ be a Bregman nonspreading mapping. Then $T$ has a fixed point.

Proof. Let $\mu$ a Banach limit on $\ell^{\infty}$ and $x \in C$ be such that $\left\{T^{n} x\right\}_{n \in \mathbb{N}}$ is bounded. For any $n$ in $\mathbb{N}$ we have

$$
\begin{aligned}
& D_{g}\left(T^{n} x, T y\right)+D_{g}\left(T y, T^{n} x\right) \\
& \quad \leq D_{g}\left(T^{n} x, y\right)+D_{g}\left(T y, T^{n-1} x\right), \quad \forall y \in C .
\end{aligned}
$$

This implies that

$$
\begin{aligned}
& \mu_{n} D_{g}\left(T^{n} x, T y\right)+\mu_{n} D_{g}\left(T y, T^{n} x\right) \\
& \quad \leq \mu_{n} D_{g}\left(T^{n} x, y\right)+\mu_{n} D_{g}\left(T y, T^{n-1} x\right), \quad \forall y \in C .
\end{aligned}
$$

Thus we have

$$
\mu_{n} D_{g}\left(T^{n} x, T y\right) \leq \mu_{n} D_{g}\left(T^{n} x, y\right), \quad \forall y \in C .
$$

It follows from Theorem 13 that $F(T) \neq \emptyset$.

\section{Weak and Strong Convergence Theorems for Bregman Nonspreading Mappings}

In this section, we prove weak and strong convergence theorems concerning Bregman nonspreading mappings in a reflexive Banach space.

Lemma 15. Let $C$ be a nonempty, closed, and convex subset of a reflexive Banach space $E$. Let $g: E \rightarrow \mathbb{R}$ be a strictly convex and Gâteaux differentiable function. Let $T: C \rightarrow C$ be a Bregman skew quasi-nonexpansive mapping with a nonempty fixed point set $F(T)$. Let $\left\{x_{n}\right\}_{n \in \mathbb{N}}$ and $\left\{y_{n}\right\}_{n \in \mathbb{N}}$ be two sequences defined by (1) such that $\left\{\beta_{n}\right\}_{n \in \mathbb{N}}$ and $\left\{\gamma_{n}\right\}_{n \in \mathbb{N}}$ are arbitrary sequences in $[0,1]$. Then the following assertions hold:

(1) $\max \left\{D_{g}\left(x_{n+1}, z\right), D_{g}\left(y_{n}, z\right)\right\} \leq D_{g}\left(x_{n}, z\right)$ for all $z$ in $F(T)$ and $n=1,2, \ldots$,

(2) $\lim _{n \rightarrow \infty} D_{g}\left(x_{n}, z\right)$ exists for any $z$ in $F(T)$.

Proof. Let $z \in F(T)$. In view of (23), we have

$$
\begin{aligned}
D_{g}\left(y_{n}, z\right) & =D_{g}\left(\beta_{n} T x_{n}+\left(1-\beta_{n}\right) x_{n}, z\right) \\
& \leq \beta_{n} D_{g}\left(T x_{n}, z\right)+\left(1-\beta_{n}\right) D_{g}\left(x_{n}, z\right) \\
& \leq \beta_{n} D_{g}\left(x_{n}, z\right)+\left(1-\beta_{n}\right) D_{g}\left(x_{n}, z\right) \\
& =D_{g}\left(x_{n}, z\right) .
\end{aligned}
$$

Consequently,

$$
\begin{aligned}
D_{g}\left(x_{n+1}, z\right) & =D_{g}\left(\gamma_{n} T y_{n}+\left(1-\gamma_{n}\right) x_{n}, z\right) \\
& \leq \gamma_{n} D_{g}\left(T y_{n}, z\right)+\left(1-\gamma_{n}\right) D_{g}\left(x_{n}, z\right) \\
& \leq \gamma_{n} D_{g}\left(y_{n}, z\right)+\left(1-\gamma_{n}\right) D_{g}\left(x_{n}, z\right) \\
& \leq \gamma_{n} D_{g}\left(x_{n}, z\right)+\left(1-\gamma_{n}\right) D_{g}\left(x_{n}, z\right) \\
& =D_{g}\left(x_{n}, z\right) .
\end{aligned}
$$

This implies that $\left\{D_{g}\left(x_{n}, z\right)\right\}_{n \in \mathbb{N}}$ is a bounded and nonincreasing sequence for all $z$ in $F(T)$. Thus we have that $\lim _{n \rightarrow \infty} D_{g}\left(x_{n}, z\right)$ exists for any $z$ in $F(T)$.

Theorem 16. Let $C$ be a nonempty, closed, and convex subset of a reflexive Banach space $E$. Let $g: E \rightarrow \mathbb{R}$ be strictly convex, Gâteaux differentiable, locally bounded, and locally uniformly convex on E. Let $T: C \rightarrow C$ be a Bregman nonspreading and Bregman skew quasi-nonexpansive mapping. Let $\left\{\beta_{n}\right\}_{n \in \mathbb{N}}$ and $\left\{\gamma_{n}\right\}_{n \in \mathbb{N}}$ be sequences in $[0,1]$, and let $\left\{x_{n}\right\}_{n \in \mathbb{N}}$ be a sequence with $x_{1}$ in $C$ defined by (1).

(a) If $\left\{x_{n}\right\}_{n \in \mathbb{N}}$ is bounded and $\liminf _{n \rightarrow \infty}\left\|T x_{n}-x_{n}\right\|=0$, then the fixed point set $F(T) \neq \emptyset$.

(b) Assume $F(T) \neq \emptyset$. Then $\left\{x_{n}\right\}_{n \in \mathbb{N}}$ is bounded.

(i) $\lim _{n \rightarrow \infty}\left\|T x_{n}-x_{n}\right\|=0$ when $\liminf _{n \rightarrow \infty} \gamma_{n}(1-$ $\left.\gamma_{n}\right)>0$ and $\lim _{n \rightarrow \infty} \beta_{n}=1$.

(ii) $\liminf _{n \rightarrow \infty}\left\|T x_{n}-x_{n}\right\|=0$ when either

(1) $\limsup _{n \rightarrow \infty} \gamma_{n}\left(1-\gamma_{n}\right)>0$ and $\lim _{n \rightarrow \infty} \beta_{n}=1$ or

(2) $\liminf _{n \rightarrow \infty} \gamma_{n}\left(1-\gamma_{n}\right)>0$ and $\lim \sup _{n \rightarrow \infty} \beta_{n}=1$.

Proof. Assume that $\left\{x_{n}\right\}_{n \in \mathbb{N}}$ is bounded and $\liminf _{n \rightarrow \infty}\left\|T x_{n}-x_{n}\right\|=0$. Consequently, there is a bounded subsequence $\left\{T x_{n_{k}}\right\}_{k \in \mathbb{N}}$ of $\left\{T x_{n}\right\}_{n \in \mathbb{N}}$ such that $\lim _{k \rightarrow \infty}\left\|T x_{n_{k}}-x_{n_{k}}\right\|=0$. Since $\nabla g$ is uniformly normto-norm continuous on bounded subsets of $E$ (see, e.g., [14]),

$$
\lim _{k \rightarrow \infty}\left\|\nabla g\left(T x_{n_{k}}\right)-\nabla g\left(x_{n_{k}}\right)\right\|=0
$$


In view of Proposition 9, we conclude that $\mathrm{BA}\left(C,\left\{x_{n_{k}}\right\}\right)=\{z\}$ for some $z$ in $C$. Let

$$
\begin{array}{r}
M_{2}=\sup \left\{\|T(z)\|,\left\|T x_{n_{k}}\right\|,\|\nabla g(z)\|,\right. \\
\|\nabla g(T z)\|: k \in \mathbb{N}\}<+\infty .
\end{array}
$$

It follows from Lemma 11 that

$$
\begin{aligned}
D_{g}( & \left.x_{n_{k}}, T z\right) \\
\leq & D_{g}\left(x_{n_{k}}, z\right)+D_{g}\left(T x_{n_{k}}, x_{n_{k}}\right) \\
& +\left\langle x_{n_{k}}-T x_{n_{k}}, \nabla g(z)-\nabla g(T z)\right\rangle \\
& +\left\langle T x_{n_{k}}-T z, \nabla g\left(x_{n_{k}}\right)-\nabla g\left(T x_{n_{k}}\right)\right\rangle \\
\leq & D_{g}\left(x_{n_{k}}, z\right)+D_{g}\left(T x_{n_{k}}, x_{n_{k}}\right) \\
& +\left\|x_{n_{k}}-T x_{n_{k}}\right\|\|\nabla g(z)-\nabla g(T z)\| \\
& +\left\|T x_{n_{k}}-T z\right\|\left\|\nabla g\left(x_{n_{k}}\right)-\nabla g\left(T x_{n_{k}}\right)\right\| \\
\leq & D_{g}\left(x_{n_{k}}, z\right)+D_{g}\left(T x_{n_{k}}, x_{n_{k}}\right) \\
& +2 M_{2}\left\|x_{n_{k}}-T x_{n_{k}}\right\| \\
& +2 M_{2}\left\|\nabla g\left(x_{n_{k}}\right)-\nabla g\left(T x_{n_{k}}\right)\right\|, \quad k=1,2, \ldots
\end{aligned}
$$

This implies

$$
\limsup _{k \rightarrow \infty} D_{g}\left(x_{n_{k}}, T z\right) \leq \limsup _{k \rightarrow \infty} D_{g}\left(x_{n_{k}}, z\right) .
$$

From the Bregman-Opial-like property, we obtain $T z=z$.

Let $F(T) \neq \emptyset$ and let $z \in F(T)$. It follows from Lemma 15 that $\lim _{n \rightarrow \infty}\left\|x_{n}-z\right\|$ exists and hence $\left\{x_{n}\right\}_{n \in \mathbb{N}}$ is bounded. This implies that the sequence $\left\{T y_{n}\right\}_{n \in \mathbb{N}}$ is bounded too. Let $s_{1}=\sup \left\{\left\|x_{n}\right\|,\left\|T y_{n}\right\|: n \in \mathbb{N}\right\}<\infty$. In view of (23), we obtain a continuous, strictly increasing, and convex function $\rho_{s_{1}}:[0,+\infty) \rightarrow[0,+\infty)$ with $\rho_{s_{1}}(0)=0$ such that

$$
\begin{aligned}
D_{g}\left(x_{n+1}, z\right)= & D_{g}\left(\gamma_{n} T y_{n}+\left(1-\gamma_{n}\right) x_{n}, z\right) \\
\leq & \gamma_{n} D_{g}\left(T y_{n}, z\right)+\left(1-\gamma_{n}\right) D_{g}\left(x_{n}, z\right) \\
& -\gamma_{n}\left(1-\gamma_{n}\right) \rho_{s_{1}}\left(\left\|T y_{n}-x_{n}\right\|\right) \\
\leq & \gamma_{n} D_{g}\left(y_{n}, z\right)+\left(1-\gamma_{n}\right) D_{g}\left(x_{n}, z\right) \\
& -\gamma_{n}\left(1-\gamma_{n}\right) \rho_{s_{1}}\left(\left\|T y_{n}-x_{n}\right\|\right) \\
\leq & \gamma_{n} D_{g}\left(x_{n}, z\right)+\left(1-\gamma_{n}\right) D_{g}\left(x_{n}, z\right) \\
& -\gamma_{n}\left(1-\gamma_{n}\right) \rho_{s_{1}}\left(\left\|T y_{n}-x_{n}\right\|\right) \\
= & D_{g}\left(x_{n}, z\right)-\gamma_{n}\left(1-\gamma_{n}\right) \rho_{s_{1}}\left(\left\|T y_{n}-x_{n}\right\|\right) .
\end{aligned}
$$

Consequently, we conclude that

$$
\begin{aligned}
& \gamma_{n}\left(1-\gamma_{n}\right) \rho_{s_{1}}\left(\left\|T y_{n}-x_{n}\right\|\right) \\
& \leq D_{g}\left(x_{n}, z\right)-D_{g}\left(x_{n+1}, z\right) \\
& \quad \longrightarrow 0, \quad \text { as } n \longrightarrow \infty .
\end{aligned}
$$

It follows that

$\liminf _{n \rightarrow \infty} \rho_{s_{1}}\left(\left\|T y_{n}-x_{n}\right\|\right)=0$ whenever $\limsup _{n \rightarrow \infty} \gamma_{n}\left(1-\gamma_{n}\right)>0$.

From the property of $\rho_{s_{1}}$ we deduce that

$$
\liminf _{n \rightarrow \infty}\left\|T y_{n}-x_{n}\right\|=0 \text { whenever } \limsup _{n \rightarrow \infty} \gamma_{n}\left(1-\gamma_{n}\right)>0 \text {. }
$$

In the same manner, we also obtain that

$$
\lim _{n \rightarrow \infty}\left\|T y_{n}-x_{n}\right\|=0 \text { whenever } \liminf _{n \rightarrow \infty} \gamma_{n}\left(1-\gamma_{n}\right)>0
$$

Since $\nabla g$ is uniformly norm-to-norm continuous on bounded subsets of $E$ (see, e.g., [14]), we arrive at

$$
\lim _{n \rightarrow \infty}\left\|\nabla g\left(T y_{n}\right)-\nabla g\left(x_{n}\right)\right\|=0
$$

On the other hand, from (1) we get

$$
\begin{aligned}
T x_{n}-y_{n} & =\left(1-\beta_{n}\right)\left(T x_{n}-x_{n}\right), \\
x_{n}-y_{n} & =\beta_{n}\left(x_{n}-T x_{n}\right) .
\end{aligned}
$$

Assuming first $\liminf _{n \rightarrow \infty} \gamma_{n}\left(1-\gamma_{n}\right)>0$. By (60) we see that

$$
\begin{aligned}
M_{3}:=\sup \{ & \left\|\nabla g\left(x_{n}\right)\right\|,\left\|\nabla g\left(T x_{n}\right)\right\|, \\
& \left.\left\|\nabla g\left(T y_{n}\right)\right\|: n \in \mathbb{N}\right\}<+\infty .
\end{aligned}
$$

Since $T$ is Bregman nonspreading, in view of (24), (25), and (62), we obtain

$$
\begin{aligned}
D_{g}( & \left.x_{n}, T x_{n}\right) \\
= & D_{g}\left(x_{n}, T y_{n}\right)+D_{g}\left(T y_{n}, T x_{n}\right) \\
& +\left\langle x_{n}-T y_{n}, \nabla g\left(T y_{n}\right)-\nabla g\left(T x_{n}\right)\right\rangle \\
\leq & D_{g}\left(x_{n}, T y_{n}\right) \\
& +\left[D_{g}\left(T y_{n}, x_{n}\right)+D_{g}\left(T x_{n}, y_{n}\right)-D_{g}\left(T x_{n}, T y_{n}\right)\right] \\
& +\left\|x_{n}-T y_{n}\right\|\left\|\nabla g\left(T y_{n}\right)-\nabla g\left(T x_{n}\right)\right\|
\end{aligned}
$$




$$
\begin{aligned}
\leq & D_{g}\left(x_{n}, T y_{n}\right) \\
& +\left[-D_{g}\left(x_{n}, T y_{n}\right)+\left\langle x_{n}-T y_{n}, \nabla g\left(x_{n}\right)-\nabla g\left(T y_{n}\right)\right\rangle\right] \\
& +\left[-D_{g}\left(y_{n}, T x_{n}\right)+\left\langle y_{n}-T x_{n}, \nabla g\left(y_{n}\right)-\nabla g\left(T x_{n}\right)\right\rangle\right] \\
& +\left\|x_{n}-T y_{n}\right\|\left\|\nabla g\left(T y_{n}\right)-\nabla g\left(T x_{n}\right)\right\| \\
\leq & \left\|x_{n}-T y_{n}\right\|\left\|\nabla g\left(x_{n}\right)-\nabla g\left(T y_{n}\right)\right\| \\
& +\left\|y_{n}-T x_{n}\right\|\left\|\nabla g\left(y_{n}\right)-\nabla g\left(T x_{n}\right)\right\| \\
& +\left\|x_{n}-T y_{n}\right\|\left\|\nabla g\left(T y_{n}\right)-\nabla g\left(T x_{n}\right)\right\| \\
= & \left(1-\beta_{n}\right)\left\|x_{n}-T x_{n}\right\|\left\|\nabla g\left(y_{n}\right)-\nabla g\left(T x_{n}\right)\right\| \\
& +\left\|x_{n}-T y_{n}\right\|\left[\| \nabla g\left(x_{n}\right)-\nabla g\left(T y_{n}\right)\right. \\
& \left.\quad+\left\|\nabla g\left(T y_{n}\right)-\nabla g\left(T x_{n}\right)\right\|\right] \\
\leq & 2\left(1-\beta_{n}\right) M_{3}\left\|x_{n}-T x_{n}\right\|+4 M_{3}\left\|x_{n}-T y_{n}\right\| .
\end{aligned}
$$

When $\lim _{n \rightarrow \infty} \beta_{n}=1$, we conclude that

$$
\lim _{n \rightarrow \infty} D_{g}\left(x_{n}, T x_{n}\right)=0 .
$$

In view of Lemma 2, we have that

$$
\lim _{n \rightarrow \infty}\left\|x_{n}-T x_{n}\right\|=0 .
$$

Finally, we assume $\lim \sup _{n \rightarrow \infty} \gamma_{n}\left(1-\gamma_{n}\right)>0$ and $\lim _{n \rightarrow \infty} \beta_{n}=1$ instead. By (59) we have subsequences $\left\{x_{n_{k}}\right\}_{k \in \mathbb{N}}$ and $\left\{y_{n_{k}}\right\}_{k \in \mathbb{N}}$ of $\left\{x_{n}\right\}_{n \in \mathbb{N}}$ and $\left\{y_{n}\right\}_{n \in \mathbb{N}}$, respectively, such that

$$
\lim _{k \rightarrow \infty}\left\|T y_{n_{k}}-x_{n_{k}}\right\|=0
$$

Replacing $M_{3}$ with the finite number $\sup \left\{\left\|\nabla g\left(x_{n_{k}}\right)\right\|\right.$, $\left.\left\|\nabla g\left(T x_{n_{k}}\right)\right\|,\left\|\nabla g\left(T y_{n_{k}}\right)\right\|: k \in \mathbb{N}\right\}<+\infty$, and dealing with the subsequences $\left\{x_{n_{k}}\right\}_{k \in \mathbb{N}}$ and $\left\{y_{n_{k}}\right\}_{k \in \mathbb{N}}$ in (60) and (62). Passing to a further subsequence if necessary, we will arrive at the desired conclusion with (66) that $\lim _{k \rightarrow \infty}\left\|T x_{n_{k}}-x_{n_{k}}\right\|=0$. Hence, $\liminf _{n \rightarrow \infty}\left\|T x_{n}-x_{n}\right\|=0$. The other case can be argued similarly.

Theorem 17. Let $C$ be a nonempty, closed, and convex subset of a reflexive Banach space $E$. Let $g: E \rightarrow \mathbb{R}$ be strictly convex, Gâteaux differentiable, locally bounded, and locally uniformly convex on $E$. Let $T: C \rightarrow C$ be a Bregman nonspreading and Bregman skew quasi-nonexpansive mapping with $F(T) \neq \emptyset$. Let $\left\{\beta_{n}\right\}_{n \in \mathbb{N}}$ and $\left\{\gamma_{n}\right\}_{n \in \mathbb{N}}$ be sequences in $[0,1]$, and let $\left\{x_{n}\right\}_{n \in \mathbb{N}}$ be a sequence with $x_{1}$ in $C$ defined by (1). Assume that $\liminf _{n \rightarrow \infty} \gamma_{n}\left(1-\gamma_{n}\right)>0$ and $\lim _{n \rightarrow \infty} \beta_{n}=1$. Then $\left\{x_{n}\right\}_{n \in \mathbb{N}}$ converges weakly to a fixed point of $T$.

Proof. It follows from Theorem 16 that $\left\{x_{n}\right\}_{n \in N}$ is bounded and $\lim _{n \rightarrow \infty}\left\|T x_{n}-x_{n}\right\|=0$. Since $E$ is reflexive, then there exists a subsequence $\left\{x_{n_{i}}\right\}_{i \in \mathbb{N}}$ of $\left\{x_{n}\right\}_{n \in \mathbb{N}}$ such that $x_{n_{i}} \rightarrow p \in C$ as $i \rightarrow \infty$. By Proposition 12, $p \in F(T)$. We claim that $x_{n} \rightarrow p$ as $n \rightarrow \infty$. If not, then there exists a subsequence $\left\{x_{n_{j}}\right\}_{j \in \mathbb{N}}$ of $\left\{x_{n}\right\}_{n \in N}$ such that $\left\{x_{n_{j}}\right\}_{j \in \mathbb{N}}$ converges weakly to some $q$ in $C$ with $p \neq q$. In view of Proposition 12 again, we conclude that $q \in F(T)$. By Lemma $15, \lim _{n \rightarrow \infty} D_{g}\left(x_{n}, z\right)$ exists for all $z$ in $F(T)$. Thus we obtain by the Bregman-Opiallike property that

$$
\begin{aligned}
\lim _{n \rightarrow \infty} D_{g}\left(x_{n}, p\right) & \\
= & \lim _{i \rightarrow \infty} D_{g}\left(x_{n_{i}}, p\right)<\lim _{i \rightarrow \infty} D_{g}\left(x_{n_{i}}, q\right) \\
= & \lim _{n \rightarrow \infty} D_{g}\left(x_{n}, q\right)=\lim _{j \rightarrow \infty} D_{g}\left(x_{n_{j}}, q\right) \\
< & \lim _{j \rightarrow \infty} D_{g}\left(x_{n_{j}}, p\right)=\lim _{n \rightarrow \infty} D_{g}\left(x_{n}, p\right) .
\end{aligned}
$$

This is a contradiction. Thus we have $p=q$, and the desired assertion follows.

Theorem 18. Let $C$ be a nonempty, compact, and convex subset of a reflexive Banach space $E$. Let $g: E \rightarrow \mathbb{R}$ be strictly convex, Gâteaux differentiable, locally bounded, and uniformly convex on bounded sets. Let $T: C \rightarrow C$ be a Bregman nonspreading and Bregman skew quasi-nonexpansive mapping. Let $\left\{\beta_{n}\right\}_{n \in \mathbb{N}}$ and $\left\{\gamma_{n}\right\}_{n \in \mathbb{N}}$ be sequences in $[0,1]$. Assume that either $\limsup _{n \rightarrow \infty} \gamma_{n}\left(1-\gamma_{n}\right)>0$ and $\lim _{n \rightarrow \infty} \beta_{n}=1$ or $\liminf \operatorname{in}_{n \rightarrow \infty} \gamma_{n}\left(1-\gamma_{n}\right)>0$ and $\lim \sup _{n \rightarrow \infty} \beta_{n}=1$. Let $\left\{x_{n}\right\}_{n \in \mathbb{N}}$ be a sequence with $x_{1}$ in $C$ defined by (1). Then $\left\{x_{n}\right\}_{n \in \mathbb{N}}$ converges strongly to a fixed point $z$ of $T$.

Proof. By Corollary 14, we see that the fixed point set $F(T)$ of $T$ is nonempty. In view of Theorem 16 , we obtain that $\left\{x_{n}\right\}_{n \in \mathbb{N}}$ is bounded and lim inf $\operatorname{li\infty }_{n \rightarrow \infty}\left\|T x_{n}-x_{n}\right\|=0$. By the compactness of $C$, there exists a subsequence $\left\{x_{n_{k}}\right\}_{k \in \mathbb{N}}$ of $\left\{x_{n}\right\}_{n \in \mathbb{N}}$ such that $\left\{x_{n_{k}}\right\}_{k \in \mathbb{N}}$ converges strongly to some $z$ in $C$. In view of Lemma 2 we deduce that $\lim _{k \rightarrow \infty} D_{g}\left(x_{n_{k}}, z\right)=0$. We can even assume that $\lim _{k \rightarrow \infty}\left\|T x_{n_{k}}-x_{n_{k}}\right\|=0$, and in particular, $\left\{T x_{n_{k}}\right\}_{k \in \mathbb{N}}$ is bounded. Since $\nabla g$ is uniformly norm-to-norm continuous on bounded subsets of $E$ (see, e.g., [14]),

$$
\lim _{k \rightarrow \infty}\left\|\nabla g\left(T x_{n_{k}}\right)-\nabla g\left(x_{n_{k}}\right)\right\|=0 \text {. }
$$

Let $M_{4}=\sup \left\{\|T z\|,\left\|T x_{n_{k}}\right\|,\|\nabla g(z)\|,\|\nabla g(T z)\|: k \in \mathbb{N}\right\}<$ $+\infty$. In view of Lemma 11, we obtain

$$
\begin{aligned}
D_{g}( & \left.x_{n_{k}}, T z\right) \\
\leq & D_{g}\left(x_{n_{k}}, z\right)+D_{g}\left(T x_{n_{k}}, x_{n_{k}}\right) \\
& +\left\langle x_{n_{k}}-T x_{n_{k}}, \nabla g(z)-\nabla g(T z)\right\rangle \\
& +\left\langle T x_{n_{k}}-T z, \nabla g\left(x_{n_{k}}\right)-\nabla g\left(T x_{n_{k}}\right)\right\rangle \\
\leq & D_{g}\left(x_{n_{k}}, z\right)+D_{g}\left(T x_{n_{k}}, x_{n_{k}}\right) \\
& +2 M_{4}\left[\left\|x_{n_{k}}-T x_{n_{k}}\right\|+\left\|\nabla g\left(x_{n_{k}}\right)-\nabla g\left(T x_{n_{k}}\right)\right\|\right]
\end{aligned}
$$

for all $k$ in $\mathbb{N}$.

It follows that $\lim _{k \rightarrow \infty}\left\|x_{n_{k}}-T z\right\|=0$. Thus we have $T z=z$. In view of Lemmas 15 and 2 , we conclude that $\lim _{n \rightarrow \infty}\left\|x_{n}-z\right\|=0$. Therefore, $z$ is the strong limit of the sequence $\left\{x_{n}\right\}_{n \in \mathbb{N}}$. 


\section{Bregman-Ishikawa's Type Iteration for Bregman Nonspreading Mappings}

We propose the following Bregman-Ishikawa's type iteration. Let $E$ be a reflexive Banach space and let $g: E \rightarrow \mathbb{R}$ be a strictly convex and Gâteaux differentiable function. Let $C$ be a nonempty, closed, and convex subset of $E$. Let $T: C \rightarrow$ $C$ be a Bregman nonspreading mapping such that the fixed point set $F(T)$ is nonempty. Let $\left\{x_{n}\right\}_{n \in \mathbb{N}}$ and $\left\{y_{n}\right\}_{n \in \mathbb{N}}$ be two sequences defined by

$$
\begin{gathered}
y_{n}=\nabla g^{*}\left[\beta_{n} \nabla g\left(T x_{n}\right)+\left(1-\beta_{n}\right) \nabla g\left(x_{n}\right)\right], \\
x_{n+1}=\operatorname{proj}_{C}^{g}\left(\nabla g^{*}\left[\gamma_{n} \nabla g\left(T y_{n}\right)+\left(1-\gamma_{n}\right) \nabla g\left(x_{n}\right)\right]\right),
\end{gathered}
$$

where $\left\{\beta_{n}\right\}_{n \in \mathbb{N}}$ and $\left\{\gamma_{n}\right\}_{n \in \mathbb{N}}$ are arbitrary sequences in $[0,1]$.

Lemma 19. Let $C$ be a nonempty, closed, and convex subset of a reflexive Banach space $E$. Let $g: E \rightarrow \mathbb{R}$ be a strongly coercive Bregman function. Let $T: C \rightarrow C$ be a Bregman quasi-nonexpansive mapping. Let $\left\{x_{n}\right\}_{n \in \mathbb{N}}$ and $\left\{y_{n}\right\}_{n \in \mathbb{N}}$ be two sequences defined by (71) such that $\left\{\beta_{n}\right\}_{n \in \mathbb{N}}$ and $\left\{\gamma_{n}\right\}_{n \in \mathbb{N}}$ are arbitrary sequences in $[0,1]$. Then the following assertions hold:

(1) $\max \left\{D_{g}\left(z, x_{n+1}\right), D_{g}\left(z, y_{n}\right)\right\} \leq D_{g}\left(z, x_{n}\right)$ for all $z$ in $F(T)$ and $n=1,2, \ldots$,

(2) $\lim _{n \rightarrow \infty} D_{g}\left(z, x_{n}\right)$ exists for any $z$ in $F(T)$.

Proof. Let $z \in F(T)$. In view of Lemma 8 and (71), we conclude that

$$
\begin{aligned}
D_{g}\left(z, y_{n}\right) & =D_{g}\left(z, \nabla g^{*}\left[\beta_{n} \nabla g\left(T x_{n}\right)+\left(1-\beta_{n}\right) \nabla g\left(x_{n}\right)\right]\right) \\
& =V\left(z, \beta_{n} \nabla g\left(T x_{n}\right)+\left(1-\beta_{n}\right) \nabla g\left(x_{n}\right)\right) \\
& \leq \beta_{n} V\left(z, \nabla g\left(T x_{n}\right)\right)+\left(1-\beta_{n}\right) V\left(z, \nabla g\left(x_{n}\right)\right) \\
& =\beta_{n} D_{g}\left(z, T x_{n}\right)+\left(1-\beta_{n}\right) D_{g}\left(z, x_{n}\right) \\
& \leq \beta_{n} D_{g}\left(z, x_{n}\right)+\left(1-\beta_{n}\right) D_{g}\left(z, x_{n}\right) \\
& =D_{g}\left(z, x_{n}\right) .
\end{aligned}
$$

Consequently, using (35) we have

$$
\begin{aligned}
& D_{g}\left(z, x_{n+1}\right) \\
& =D_{g}\left(z, \operatorname{proj}_{C}^{g}\left(\nabla g^{*}\left[\gamma_{n} \nabla g\left(T y_{n}\right)+\left(1-\gamma_{n}\right) \nabla g\left(x_{n}\right)\right]\right)\right) \\
& \leq D_{g}\left(z, \nabla g^{*}\left[\gamma_{n} \nabla g\left(T y_{n}\right)+\left(1-\gamma_{n}\right) \nabla g\left(x_{n}\right)\right]\right) \\
& =V\left(z, \gamma_{n} \nabla g\left(T y_{n}\right)+\left(1-\gamma_{n}\right) \nabla g\left(x_{n}\right)\right) \\
& \leq \gamma_{n} V\left(z, \nabla g\left(T y_{n}\right)\right)+\left(1-\gamma_{n}\right) V\left(z, \nabla g\left(x_{n}\right)\right) \\
& =\gamma_{n} D_{g}\left(z, T y_{n}\right)+\left(1-\gamma_{n}\right) D_{g}\left(z, x_{n}\right) \\
& \leq \gamma_{n} D_{g}\left(z, y_{n}\right)+\left(1-\gamma_{n}\right) D_{g}\left(z, x_{n}\right) \\
& \leq \gamma_{n} D_{g}\left(z, x_{n}\right)+\left(1-\gamma_{n}\right) D_{g}\left(z, x_{n}\right) \\
& =D_{g}\left(z, x_{n}\right) .
\end{aligned}
$$

This implies that $\left\{D_{g}\left(z, x_{n}\right)\right\}_{n \in \mathbb{N}}$ is a bounded and nonincreasing sequence for all $z$ in $F(T)$. Thus we have that $\lim _{n \rightarrow \infty} D_{g}\left(z, x_{n}\right)$ exists for any $z$ in $F(T)$.

Theorem 20. Let $C$ be a nonempty, closed, and convex subset of a reflexive Banach space $E$. Let $g: E \rightarrow \mathbb{R}$ be a strongly coercive Bregman function which is locally bounded, locally uniformly convex, and locally uniformly smooth on E. Let T: $C \rightarrow C$ be a Bregman nonspreading mapping. Let $\left\{\alpha_{n}\right\}_{n \in \mathbb{N}}$ and $\left\{\beta_{n}\right\}_{n \in \mathbb{N}}$ be two sequences in $[0,1]$ satisfying the control condition:

$$
\sum_{n=1}^{\infty} \gamma_{n} \beta_{n}\left(1-\beta_{n}\right)=+\infty .
$$

Let $\left\{x_{n}\right\}_{n \in \mathbb{N}}$ be a sequence generated by algorithm (71). Then the following are equivalent.

(1) There exists a bounded sequence $\left\{x_{n}\right\}_{n \in \mathbb{N}} \subset C$ such that $\liminf _{n \rightarrow \infty}\left\|T x_{n}-x_{n}\right\|=0$.

(2) The fixed point set $F(T) \neq \emptyset$.

Proof. The implication (1) $\Rightarrow(2)$ follows similarly as in the first part of the proof of Theorem 16.

For the implication $(2) \Rightarrow(1)$, we assume $F(T) \neq \emptyset$. The boundedness of the sequences $\left\{x_{n}\right\}_{n \in \mathbb{N}}$ and $\left\{y_{n}\right\}_{n \in \mathbb{N}}$ follows from Lemma 19 and Definition 4. Since $T$ is a Bregman quasinonexpansive mapping, for any $q$ in $F(T)$, we have

$$
D_{g}\left(q, T x_{n}\right) \leq D_{g}\left(q, x_{n}\right), \quad \forall n \in \mathbb{N} .
$$

This, together with Definition 4 and the boundedness of $\left\{x_{n}\right\}_{n \in \mathbb{N}}$, implies that $\left\{T x_{n}\right\}_{n \in \mathbb{N}}$ is bounded.

The function $g$ is bounded on bounded subsets of $E$ and therefore $\nabla g$ is also bounded on bounded subsets of $E^{*}$ (see, e.g., [12, Proposition 1.1.11] for more details). This implies that the sequences $\left\{\nabla g\left(x_{n}\right)\right\}_{n \in \mathbb{N}},\left\{\nabla g\left(y_{n}\right)\right\}_{n \in \mathbb{N}},\left\{\nabla g\left(T y_{n}\right)\right\}_{n \in \mathbb{N}}$, and $\left\{\nabla g\left(T x_{n}\right)\right\}_{n \in \mathbb{N}}$ are bounded in $E^{*}$.

In view of Proposition 7, we have that dom $g^{*}=E^{*}$ and $g^{*}$ is strongly coercive and uniformly convex on bounded subsets of $E^{*}$. Let $s_{2}=\sup \left\{\left\|\nabla g\left(x_{n}\right)\right\|,\left\|\nabla g\left(T x_{n}\right)\right\|: n \in \mathbb{N}\right\}<$ $\infty$ and let $\rho_{s_{2}}^{*}: E^{*} \rightarrow \mathbb{R}$ be the gauge of uniform convexity of the conjugate function $g^{*}$.

Claim. For any $p$ in $F(T)$ and $n$ in $\mathbb{N}$,

$$
\begin{aligned}
D_{g}\left(p, y_{n}\right) \leq & D_{g}\left(p, x_{n}\right) \\
& -\beta_{n}\left(1-\beta_{n}\right) \rho_{s_{2}}^{*}\left(\left\|\nabla g\left(x_{n}\right)-\nabla g\left(T x_{n}\right)\right\|\right) .
\end{aligned}
$$

Let $p \in F(T)$. For each $n$ in $\mathbb{N}$, it follows from the definition of Bregman distance (4), Lemma 8, (23), and (71) that

$$
\begin{aligned}
D_{g} & \left(p, y_{n}\right) \\
= & g(p)-g\left(y_{n}\right)-\left\langle p-y_{n}, \nabla g\left(y_{n}\right)\right\rangle \\
= & g(p)+g^{*}\left(\nabla g\left(y_{n}\right)\right)-\left\langle y_{n}, \nabla g\left(y_{n}\right)\right\rangle \\
& -\left\langle p, \nabla g\left(y_{n}\right)\right\rangle+\left\langle y_{n}, \nabla g\left(y_{n}\right)\right\rangle
\end{aligned}
$$




$$
\begin{aligned}
= & g(p)+g^{*}\left(\left(1-\beta_{n}\right) \nabla g\left(x_{n}\right)+\beta_{n} \nabla g\left(T x_{n}\right)\right) \\
& -\left\langle p,\left(1-\beta_{n}\right) \nabla g\left(x_{n}\right)+\beta_{n} \nabla g\left(T x_{n}\right)\right\rangle \\
\leq & \left(1-\beta_{n}\right) g(p)+\beta_{n} g(p) \\
& +\left(1-\beta_{n}\right) g^{*}\left(\nabla g\left(x_{n}\right)\right)+\beta_{n} g^{*}\left(\nabla g\left(T x_{n}\right)\right) \\
& -\beta_{n}\left(1-\beta_{n}\right) \rho_{s_{2}}^{*}\left(\left\|\nabla g\left(x_{n}\right)-\nabla g\left(T x_{n}\right)\right\|\right) \\
& -\left(1-\beta_{n}\right)\left\langle p, \nabla g\left(x_{n}\right)\right\rangle-\beta_{n}\left\langle p, \nabla g\left(T x_{n}\right)\right\rangle \\
= & \left(1-\beta_{n}\right)\left[g(p)+g^{*}\left(\nabla g\left(x_{n}\right)\right)-\left\langle p, \nabla g\left(x_{n}\right)\right\rangle\right] \\
& +\beta_{n}\left[g(p)+g^{*}\left(\nabla g\left(T x_{n}\right)\right)-\left\langle p, \nabla g\left(T x_{n}\right)\right\rangle\right] \\
& -\beta_{n}\left(1-\beta_{n}\right) \rho_{s_{2}}^{*}\left(\left\|\nabla g\left(x_{n}\right)-\nabla g\left(T x_{n}\right)\right\|\right) \\
= & \left(1-\beta_{n}\right)\left[g(p)-g\left(x_{n}\right)\right. \\
& \left.\quad+\left\langle x_{n}, \nabla g\left(x_{n}\right)\right\rangle-\left\langle p, \nabla g\left(x_{n}\right)\right\rangle\right] \\
& -\beta_{n}\left(1-\beta_{n}\right) \rho_{s_{2}}^{*}\left(\left\|\nabla g\left(x_{n}\right)-\nabla g\left(T x_{n}\right)\right\|\right) \\
& +\beta_{n}\left[g(p)-g\left(T x_{n}\right)\right. \\
& \quad+\beta_{n}\left(1-\beta_{n}\right) \rho_{s_{2}}^{*}\left(\left\|\nabla g\left(x_{n}\right)-\nabla g\left(T x_{n}\right)\right\|\right) \\
= & \left(1-\beta_{n}\right) D\left(p, x_{n}\right)+\beta_{n} D\left(p, T x_{n}\right) \\
& +\beta_{n}\left(1-\beta_{n}\right) \rho_{s_{2}}^{*}\left(\left\|\nabla g\left(x_{n}\right)-\nabla g\left(T x_{n}\right)\right\|\right) .
\end{aligned}
$$

In view of Lemma 8 and (76), we obtain

$$
\begin{aligned}
D_{g}\left(p, x_{n+1}\right) & =D_{g}\left(p, \nabla g^{*}\left[\gamma_{n} \nabla g\left(T y_{n}\right)+\left(1-\gamma_{n}\right) \nabla g\left(x_{n}\right)\right]\right) \\
= & V\left(p, \gamma_{n} \nabla g\left(T y_{n}\right)+\left(1-\gamma_{n}\right) \nabla g\left(x_{n}\right)\right) \\
\leq & \gamma_{n} V\left(p, \nabla g\left(T y_{n}\right)\right)+\left(1-\gamma_{n}\right) V\left(p, \nabla g\left(x_{n}\right)\right) \\
= & \gamma_{n} D_{g}\left(p, T y_{n}\right)+\left(1-\gamma_{n}\right) D_{g}\left(p, x_{n}\right) \\
\leq & \gamma_{n} D_{g}\left(p, y_{n}\right)+\left(1-\gamma_{n}\right) D_{g}\left(p, x_{n}\right) \\
\leq & D_{g}\left(p, x_{n}\right)-\gamma_{n} \beta_{n}\left(1-\beta_{n}\right) \rho_{s_{2}}^{*} \\
& \times\left(\left\|\nabla g\left(x_{n}\right)-\nabla g\left(T x_{n}\right)\right\|\right) .
\end{aligned}
$$

Thus we have

$$
\begin{aligned}
& \gamma_{n} \beta_{n}\left(1-\beta_{n}\right) \rho_{s_{2}}^{*}\left(\left\|\nabla g\left(x_{n}\right)-\nabla g\left(T_{n} x_{n}\right)\right\|\right) \\
& \quad \leq D_{g}\left(p, x_{n}\right)-D_{g}\left(p, x_{n+1}\right) .
\end{aligned}
$$

Since $\left\{D_{g}\left(p, x_{n}\right)\right\}_{n \in \mathbb{N}}$ converges, together with the control condition (74), we have

$$
\liminf _{n \rightarrow \infty} \rho_{s_{2}}^{*}\left(\left\|\nabla g\left(x_{n}\right)-\nabla g\left(T x_{n}\right)\right\|\right)=0 .
$$

Therefore, from the property of $\rho_{s_{2}}^{*}$ we deduce that

$$
\liminf _{n \rightarrow \infty}\left\|\nabla g\left(x_{n}\right)-\nabla g\left(T x_{n}\right)\right\|=0
$$

Since $\nabla g^{*}$ is uniformly norm-to-norm continuous on bounded subsets of $E^{*}$ (see, e.g., [14]), we arrive at

$$
\liminf _{n \rightarrow \infty}\left\|x_{n}-T x_{n}\right\|=0 \text {. }
$$

Theorem 21. Let $C$ be a nonempty, closed, and convex subset of a reflexive Banach space $E$. Let $g: E \rightarrow \mathbb{R}$ be a strongly coercive Bregman function which is locally bounded, locally uniformly convex, and locally uniformly smooth on E. Let $T$ : $C \rightarrow C$ be a Bregman nonspreading mapping with $F(T) \neq \emptyset$. Let $\left\{\alpha_{n}\right\}_{n \in \mathbb{N}}$ and $\left\{\beta_{n}\right\}_{n \in \mathbb{N}}$ be two sequences in $[0,1]$ satisfying the control conditions $\sum_{n=1}^{\infty} \gamma_{n} \beta_{n}\left(1-\beta_{n}\right)=+\infty$. Let $\left\{x_{n}\right\}_{n \in \mathbb{N}}$ be a sequence generated by the algorithm (71). Then, there exists a subsequence $\left\{x_{n_{i}}\right\}_{i \in \mathbb{N}}$ of $\left\{x_{n}\right\}_{n \in \mathbb{N}}$ which converges weakly to a fixed point of $T$ as $i \rightarrow \infty$.

Proof. It follows from Theorem 20 that $\left\{x_{n}\right\}_{n \in \mathbb{N}}$ is bounded and lim inf $\operatorname{li\infty }_{n \rightarrow \infty}\left\|T x_{n}-x_{n}\right\|=0$. Since $E$ is reflexive, then there exists a subsequence $\left\{x_{n_{i}}\right\}_{i \in \mathbb{N}}$ of $\left\{x_{n}\right\}_{n \in \mathbb{N}}$ such that $x_{n i} \rightarrow p \in$ $C$ as $i \rightarrow \infty$. In view of Proposition 12, we conclude that $p \in F(T)$ and the desired conclusion follows.

The construction of fixed points of nonexpansive mappings via Halpern's algorithm [24] has been extensively investigated recently in the current literature (see, e.g., [2] and the references therein). Numerous results have been proved on Halpern's iterations for nonexpansive mappings in Hilbert and Banach spaces (see, e.g., $[11,25,26]$ ).

Before dealing with the strong convergence of a Halperntype iterative algorithm, we need the following lemmas.

Lemma 22 (see [27]). Let $\left\{a_{n}\right\}_{n \in \mathbb{N}}$ be a sequence in $\mathbb{R}$ with a subsequence $\left\{a_{n_{i}}\right\}_{i \in \mathbb{N}}$ such that $a_{n_{i}}<a_{n_{i}+1}$ for all $i$ in $\mathbb{N}$. Then there exists another subsequence $\left\{a_{m_{k}}\right\}_{k \in \mathbb{N}}$ such that for all (sufficiently large) number $k$ one have

$$
a_{m_{k}} \leq a_{m_{k}+1}, \quad a_{k} \leq a_{m_{k}+1} .
$$

In fact, one can set $m_{k}=\max \left\{j \leq k: a_{j}<a_{j+1}\right\}$.

Lemma 23 (see [28]). Let $\left\{s_{n}\right\}_{n \in \mathbb{N}}$ be a sequence of nonnegative real numbers satisfying

$$
s_{n+1} \leq\left(1-\gamma_{n}\right) s_{n}+\gamma_{n} \delta_{n}, \quad \forall n \geq 1,
$$

where $\left\{\gamma_{n}\right\}_{n \in \mathbb{N}}$ and $\left\{\delta_{n}\right\}_{n \in \mathbb{N}}$ satisfy the following conditions:

(i) $\left\{\gamma_{n}\right\}_{n \in \mathbb{N}} \subset[0,1]$ and $\sum_{n=1}^{\infty} \gamma_{n}=+\infty$, or, equivalently, $\Pi_{n=1}^{\infty}\left(1-\gamma_{n}\right)=0$,

(ii) $\lim \sup _{n \rightarrow \infty} \delta_{n} \leq 0$, or

(iii) $\sum_{n=1}^{\infty} \gamma_{n} \delta_{n}<\infty$.

Then, $\lim _{n \rightarrow \infty} s_{n}=0$. 
Theorem 24. Let $C$ be a nonempty, closed, and convex subset of a reflexive Banach space $E$. Let $g: E \rightarrow \mathbb{R}$ be a strongly coercive Bregman function which is locally bounded, locally uniformly convex, and locally uniformly smooth on E. Let $T$ : $C \rightarrow C$ be a Bregman nonspreading mapping with $F(T) \neq \emptyset$. Let $\left\{\alpha_{n}\right\}_{n \in \mathbb{N}}$ and $\left\{\beta_{n}\right\}_{n \in \mathbb{N}}$ be two sequences in $[0,1]$ satisfying the following control conditions:

(a) $\lim _{n \rightarrow \infty} \alpha_{n}=0$;

(b) $\sum_{n=1}^{\infty} \alpha_{n}=+\infty$;

(c) $0<\liminf _{n \rightarrow \infty} \beta_{n} \leq \lim \sup _{n \rightarrow \infty} \beta_{n}<1$.

Let $\left\{x_{n}\right\}_{n \in \mathbb{N}}$ be a sequence generated by

$$
\begin{gathered}
u \in C, x_{1} \in C \text { chosen arbitrarily, } \\
y_{n}=\nabla g^{*}\left[\beta_{n} \nabla g\left(x_{n}\right)+\left(1-\beta_{n}\right) \nabla g\left(T x_{n}\right)\right], \\
x_{n+1}=\operatorname{proj}_{C}^{g}\left(\nabla g ^ { * } \left[\alpha_{n} \nabla g(u)\right.\right. \\
\left.\left.+\left(1-\alpha_{n}\right) \nabla g\left(y_{n}\right)\right]\right) \text { for } n \text { in } \mathbb{N} .
\end{gathered}
$$

Then the sequence $\left\{x_{n}\right\}_{n \in \mathbb{N}}$ defined in (85) converges strongly to $\operatorname{proj}_{F(T)}^{g}$ us $n \rightarrow \infty$.

Proof. We divide the proof into several steps. In view of Lemma 10, we conclude that $F(T)$ is closed and convex. Set

$$
z=\operatorname{proj}_{F(T)}^{g} u .
$$

Step 1. We prove that $\left\{x_{n}\right\}_{n \in \mathbb{N}}$ and $\left\{y_{n}\right\}_{n \in \mathbb{N}}$ are bounded sequences in $C$.

We first show that $\left\{x_{n}\right\}_{n \in \mathbb{N}}$ is bounded. Let $p \in F(T)$ be fixed. In view of Lemma 8 and (85), we have

$$
\begin{aligned}
D_{g} & \left(p, y_{n}\right) \\
& =D_{g}\left(p, \nabla g^{*}\left[\left(1-\beta_{n}\right) \nabla g\left(x_{n}\right)+\beta_{n} \nabla g\left(T x_{n}\right)\right]\right) \\
& =V\left(p,\left[\left(1-\beta_{n}\right) \nabla g\left(x_{n}\right)+\beta_{n} \nabla g\left(T x_{n}\right)\right]\right) \\
& \leq\left(1-\beta_{n}\right) V\left(p, \nabla g\left(x_{n}\right)\right)+\beta_{n} V\left(p, \nabla g\left(T x_{n}\right)\right) \\
& =\left(1-\beta_{n}\right) D_{g}\left(p, x_{n}\right)+\beta_{n} D_{g}\left(p, T x_{n}\right) \\
& \leq\left(1-\beta_{n}\right) D_{g}\left(p, x_{n}\right)+\beta_{n} D_{g}\left(p, x_{n}\right) \\
& =D_{g}\left(p, x_{n}\right) .
\end{aligned}
$$

This, together with (71), implies that

$$
\begin{aligned}
& D_{g}\left(p, x_{n+1}\right) \\
& \quad=D_{g}\left(p, \operatorname{proj}_{C}^{g}\left(\nabla g^{*}\left[\alpha_{n} \nabla g(u)+\left(1-\alpha_{n}\right) \nabla g\left(y_{n}\right)\right]\right)\right) \\
& \quad \leq D_{g}\left(p, \nabla g^{*}\left[\alpha_{n} \nabla g(u)+\left(1-\alpha_{n}\right) \nabla g\left(y_{n}\right)\right]\right) \\
& \quad=V\left(p, \alpha_{n} \nabla g(u)+\left(1-\alpha_{n}\right) \nabla g\left(y_{n}\right)\right)
\end{aligned}
$$

$$
\begin{aligned}
& \leq \alpha_{n} V(p, \nabla g(u))+\left(1-\alpha_{n}\right) V\left(p, \nabla g\left(y_{n}\right)\right) \\
& =\alpha_{n} D_{g}(p, u)+\left(1-\alpha_{n}\right) D_{g}\left(p, y_{n}\right) \\
& \leq \alpha_{n} D_{g}(p, u)+\left(1-\alpha_{n}\right) D_{g}\left(p, y_{n}\right) \\
& \leq \alpha_{n} D_{g}(p, u)+\left(1-\alpha_{n}\right) D_{g}\left(p, x_{n}\right) \\
& \leq \max \left\{D_{g}(p, u), D_{g}\left(p, x_{n}\right)\right\} .
\end{aligned}
$$

By induction, we obtain

$$
D_{g}\left(p, x_{n+1}\right) \leq \max \left\{D_{g}(p, u), D_{g}\left(p, x_{1}\right)\right\}
$$

for all $n$ in $\mathbb{N}$. It follows from (89) that the sequence $\left\{D_{g}\left(p, x_{n}\right)\right\}_{n \in \mathbb{N}}$ is bounded and hence there exists $M_{7}>0$ such that

$$
D_{g}\left(p, x_{n}\right) \leq M_{7}, \quad \forall n \in \mathbb{N} .
$$

In view of Definition 4 , we deduce that the sequence $\left\{x_{n}\right\}_{n \in \mathbb{N}}$ is bounded. Since $T$ is a Bregman quasi-nonexpansive mapping from $C$ into itself, we conclude that

$$
D_{g}\left(p, T x_{n}\right) \leq D_{g}\left(p, x_{n}\right), \quad \forall n \in \mathbb{N} .
$$

This, together with Definition 4 and the boundedness of $\left\{x_{n}\right\}_{n \in \mathbb{N}}$, implies that $\left\{T x_{n}\right\}_{n \in \mathbb{N}}$ is bounded. The function $g$ is bounded on bounded subsets of $E$ and therefore $\nabla g$ is also bounded on bounded subsets of $E^{*}$ (see, e.g., [12, Proposition 1.1.11] for more details). This, together with Step 1, implies that the sequences $\left\{\nabla g\left(x_{n}\right)\right\}_{n \in \mathbb{N}},\left\{\nabla g\left(y_{n}\right)\right\}_{n \in \mathbb{N}}$, and $\left\{\nabla g\left(T x_{n}\right)\right\}_{n \in \mathbb{N}}$ are bounded in $E^{*}$. In view of Proposition 7, we obtain that dom $\mathrm{g}^{*}=E^{*}$ and $g^{*}$ is strongly coercive and uniformly convex on bounded subsets of $E$. Let $s_{3}=$ $\sup \left\{\left\|\nabla g\left(x_{n}\right)\right\|,\left\|\nabla g\left(T x_{n}\right)\right\|: n \in \mathbb{N}\right\}$ and let $\rho_{s_{3}}^{*}: E^{*} \rightarrow \mathbb{R}$ be the gauge of uniform convexity of the conjugate function $g^{*}$.

Step 2. We prove that

$$
\begin{aligned}
D_{g}\left(z, y_{n}\right) \leq & D_{g}\left(z, x_{n}\right)-\beta_{n}\left(1-\beta_{n}\right) \rho_{s_{3}}^{*} \\
& \times\left(\left\|\nabla g\left(x_{n}\right)-\nabla g\left(T x_{n}\right)\right\|\right), \quad \forall n \in \mathbb{N} .
\end{aligned}
$$

For each $n$ in $\mathbb{N}$, in view of the definition of Bregman distance (4), Lemma 8, and (30), we obtain

$$
\begin{aligned}
& D_{g}\left(z, y_{n}\right) \\
&= g(z)-g\left(y_{n}\right)-\left\langle z-y_{n}, \nabla g\left(y_{n}\right)\right\rangle \\
&= g(z)+g^{*}\left(\nabla g\left(y_{n}\right)\right)-\left\langle y_{n}, \nabla g\left(y_{n}\right)\right\rangle \\
&-\left\langle z, \nabla g\left(y_{n}\right)\right\rangle+\left\langle y_{n}, \nabla g\left(y_{n}\right)\right\rangle \\
&= g(z)+g^{*}\left(\left(1-\beta_{n}\right) \nabla g\left(x_{n}\right)+\beta_{n} \nabla g\left(T x_{n}\right)\right) \\
&-\left\langle z,\left(1-\beta_{n}\right) \nabla g\left(x_{n}\right)+\beta_{n} \nabla g\left(T x_{n}\right)\right\rangle
\end{aligned}
$$




$$
\begin{aligned}
& \leq\left(1-\beta_{n}\right) g(z)+\beta_{n} g(z)+\left(1-\beta_{n}\right) g^{*} \\
& \times\left(\nabla g\left(x_{n}\right)\right)+\beta_{n} g^{*}\left(\nabla g\left(T x_{n}\right)\right) \\
& -\beta_{n}\left(1-\beta_{n}\right) \rho_{s_{3}}^{*}\left(\left\|\nabla g\left(x_{n}\right)-\nabla g\left(T x_{n}\right)\right\|\right) \\
& -\left(1-\beta_{n}\right)\left\langle z, \nabla g\left(x_{n}\right)\right\rangle-\beta_{n}\left\langle z, \nabla g\left(T x_{n}\right)\right\rangle \\
& =\left(1-\beta_{n}\right)\left[g(z)+g^{*}\left(\nabla g\left(x_{n}\right)\right)-\left\langle z, \nabla g\left(x_{n}\right)\right\rangle\right] \\
& +\beta_{n}\left[g(z)+g^{*}\left(\nabla g\left(T x_{n}\right)\right)-\left\langle z, \nabla g\left(T x_{n}\right)\right\rangle\right] \\
& -\beta_{n}\left(1-\beta_{n}\right) \rho_{s_{3}}^{*}\left(\left\|\nabla g\left(x_{n}\right)-\nabla g\left(T x_{n}\right)\right\|\right) \\
& =\left(1-\beta_{n}\right)\left[g(z)-g\left(x_{n}\right)\right. \\
& \left.+\left\langle x_{n}, \nabla g\left(x_{n}\right)\right\rangle-\left\langle z, \nabla g\left(x_{n}\right)\right\rangle\right] \\
& +\beta_{n}\left[g(z)-g\left(T x_{n}\right)\right. \\
& \left.+\left\langle T x_{n}, \nabla g\left(T x_{n}\right)\right\rangle-\left\langle z, \nabla g\left(T x_{n}\right)\right\rangle\right] \\
& -\beta_{n}\left(1-\beta_{n}\right) \rho_{s_{3}}^{*}\left(\left\|\nabla g\left(x_{n}\right)-\nabla g\left(T_{n} x_{n}\right)\right\|\right) \\
& =\left(1-\beta_{n}\right) D\left(z, x_{n}\right)+\beta_{n} D\left(z, T x_{n}\right) \\
& -\beta_{n}\left(1-\beta_{n}\right) \rho_{s_{3}}^{*}\left(\left\|\nabla g\left(x_{n}\right)-\nabla g\left(T x_{n}\right)\right\|\right) \\
& \leq\left(1-\beta_{n}\right) D_{g}\left(z, x_{n}\right)+\beta_{n} D_{g}\left(z, x_{n}\right) \\
& -\beta_{n}\left(1-\beta_{n}\right) \rho_{s_{3}}^{*}\left(\left\|\nabla g\left(x_{n}\right)-\nabla g\left(T x_{n}\right)\right\|\right) \\
& =D\left(z, x_{n}\right)-\beta_{n}\left(1-\beta_{n}\right) \rho_{s_{3}}^{*} \\
& \times\left(\left\|\nabla g\left(x_{n}\right)-\nabla g\left(T x_{n}\right)\right\|\right) .
\end{aligned}
$$

In view of Lemma 8 and (92), we obtain

$$
\begin{aligned}
D_{g} & \left(z, x_{n+1}\right) \\
= & D_{g}\left(z, \operatorname{proj}_{C}^{g}\left(\nabla g^{*}\left[\alpha_{n} \nabla g(u)+\left(1-\alpha_{n}\right) \nabla g\left(y_{n}\right)\right]\right)\right) \\
\leq & D_{g}\left(z, \nabla g^{*}\left[\alpha_{n} \nabla g(u)+\left(1-\alpha_{n}\right) \nabla g\left(y_{n}\right)\right]\right) \\
= & V\left(z, \alpha_{n} \nabla g(u)+\left(1-\alpha_{n}\right) \nabla g\left(y_{n}\right)\right) \\
\leq & \alpha_{n} V(z, \nabla g(u))+\left(1-\alpha_{n}\right) V\left(z, \nabla g\left(y_{n}\right)\right) \\
= & \alpha_{n} D_{g}(z, u)+\left(1-\alpha_{n}\right) D_{g}\left(z, y_{n}\right) \\
\leq & \alpha_{n} D_{g}(z, u) \\
& +\left(1-\alpha_{n}\right)\left[D_{g}\left(z, x_{n}\right)-\beta_{n}\left(1-\beta_{n}\right) \rho_{s_{3}}^{*}\right. \\
\quad & \left.\times\left(\left\|\nabla g\left(x_{n}\right)-\nabla g\left(T x_{n}\right)\right\|\right)\right] .
\end{aligned}
$$

Let

$$
\begin{array}{r}
M_{8}:=\sup \left\{\left|D_{g}(z, u)-D_{g}\left(z, x_{n}\right)\right|+\beta_{n}\left(1-\beta_{n}\right) \rho_{s_{3}}^{*}\right. \\
\left.\times\left(\left\|\nabla g\left(x_{n}\right)-\nabla g\left(T x_{n}\right)\right\|\right): n \in \mathbb{N}\right\} .
\end{array}
$$

It follows from (94) that

$$
\begin{gathered}
\beta_{n}\left(1-\beta_{n}\right) \rho_{s_{3}}^{*}\left(\left\|\nabla g\left(x_{n}\right)-\nabla g\left(T x_{n}\right)\right\|\right) \\
\leq D_{g}\left(z, x_{n}\right)-D_{g}\left(z, x_{n+1}\right)+\alpha_{n} M_{8} .
\end{gathered}
$$

Let

$$
z_{n}=\nabla g^{*}\left[\alpha_{n} \nabla g(u)+\left(1-\alpha_{n}\right) \nabla g\left(y_{n}\right)\right]
$$

Then $x_{n+1}=\operatorname{proj}_{C}^{g}\left(z_{n}\right)$ for all $n$ in $\mathbb{N}$. In view of Lemma 8 and (92) we obtain

$$
\begin{aligned}
& D_{g}\left(z, x_{n+1}\right) \\
&=D_{g}\left(z, \operatorname{proj}_{C}^{g}\left(\nabla g^{*}\left[\alpha_{n} \nabla g(u)+\left(1-\alpha_{n}\right) \nabla g\left(y_{n}\right)\right]\right)\right) \\
& \leq D_{g}\left(z, \nabla g^{*}\left[\alpha_{n} \nabla g(u)+\left(1-\alpha_{n}\right) \nabla g\left(y_{n}\right)\right]\right) \\
&=V\left(z, \alpha_{n} \nabla g(u)+\left(1-\alpha_{n}\right) \nabla g\left(y_{n}\right)\right) \\
& \leq V\left(z, \alpha_{n} \nabla g(u)+\left(1-\alpha_{n}\right) \nabla g\left(y_{n}\right)\right. \\
&\left.\quad-\alpha_{n}(\nabla g(u)-\nabla g(z))\right) \\
& \quad-\left\langle\nabla g^{*}\left[\alpha_{n} \nabla g(u)+\left(1-\alpha_{n}\right) \nabla g\left(y_{n}\right)\right]-z,\right. \\
&\left.\quad-\alpha_{n}(\nabla g(u)-\nabla g(z))\right\rangle \\
&=V\left(z, \alpha_{n} \nabla g(z)+\left(1-\alpha_{n}\right) \nabla g\left(y_{n}\right)\right) \\
&+\alpha_{n}\left\langle z_{n}-z, \nabla g(u)-\nabla g(z)\right\rangle \\
& \leq \alpha_{n} V(z, \nabla g(z))+\left(1-\alpha_{n}\right) V\left(z, \nabla g\left(y_{n}\right)\right) \\
&+\alpha_{n}\left\langle z_{n}-z, \nabla g(u)-\nabla g(z)\right\rangle \\
&= \alpha_{n} D_{g}(z, z)+\left(1-\alpha_{n}\right) D_{g}\left(z, y_{n}\right) \\
&+\alpha_{n}\left\langle z_{n}-z, \nabla g(u)-\nabla g(z)\right\rangle \\
&=\left(1-\alpha_{n}\right) D_{g}\left(z, x_{n}\right) \\
&+\alpha_{n}\left\langle z_{n}-z, \nabla g(u)-\nabla g(z)\right\rangle . \\
&
\end{aligned}
$$

Step 3. We show that $x_{n} \rightarrow z$ as $n \rightarrow \infty$.

Case 1. If there exists $n_{0}$ in $\mathbb{N}$ such that $\left\{D_{g}\left(z, x_{n}\right)\right\}_{n=n_{0}}^{\infty}$ is nonincreasing, then $\left\{D_{g}\left(z, x_{n}\right)\right\}_{n \in \mathbb{N}}$ is convergent. Thus, we have $D_{g}\left(z, x_{n}\right)-D_{g}\left(z, x_{n+1}\right) \rightarrow 0$ as $n \rightarrow \infty$. This, together with (96) and conditions (a) and (c), implies that

$$
\lim _{n \rightarrow \infty} \rho_{s_{3}}^{*}\left(\left\|\nabla g\left(x_{n}\right)-\nabla g\left(T x_{n}\right)\right\|\right)=0
$$

Therefore, from the property of $\rho_{s_{3}}^{*}$ we deduce that

$$
\lim _{n \rightarrow \infty}\left\|\nabla g\left(x_{n}\right)-\nabla g\left(T x_{n}\right)\right\|=0 \text {. }
$$

Since $\nabla g^{*}=(\nabla g)^{-1}$ (Lemma 5) is uniformly norm-to-norm continuous on bounded subsets of $E^{*}$ (see, e.g., [14]), we arrive at

$$
\lim _{n \rightarrow \infty}\left\|x_{n}-T x_{n}\right\|=0
$$


On the other hand, we have

$$
\begin{aligned}
D_{g}( & \left.T x_{n}, y_{n}\right) \\
= & D_{g}\left(T x_{n}, \nabla g^{*}\left[\beta_{n} \nabla g\left(x_{n}\right)+\left(1-\beta_{n}\right) \nabla g\left(T x_{n}\right)\right]\right) \\
= & V\left(T x_{n}, \beta_{n} \nabla g\left(x_{n}\right)+\left(1-\beta_{n}\right) \nabla g\left(T x_{n}\right)\right) \\
\leq & \beta_{n} V\left(T x_{n}, \nabla g\left(x_{n}\right)\right) \\
& +\left(1-\beta_{n}\right) V\left(T x_{n}, \nabla g\left(T x_{n}\right)\right) \\
= & \beta_{n} D_{g}\left(T x_{n}, x_{n}\right)+\left(1-\beta_{n}\right) D_{g}\left(T x_{n}, T x_{n}\right) \\
= & \beta_{n} D_{g}\left(T x_{n}, x_{n}\right) .
\end{aligned}
$$

This, together with Lemma 2 and (101), implies that

$$
\lim _{n \rightarrow \infty} D_{g}\left(T x_{n}, y_{n}\right)=0
$$

Similarly, we have

$$
\begin{aligned}
D_{g}\left(y_{n}, z_{n}\right) & \leq \alpha_{n} D_{g}\left(y_{n}, u\right)+\left(1-\alpha_{n}\right) D_{g}\left(y_{n}, y_{n}\right) \\
& =\alpha_{n} D_{g}\left(y_{n}, u\right) \longrightarrow 0 \quad \text { as } n \longrightarrow \infty
\end{aligned}
$$

In view of Lemma 2 and (101), we conclude that

$$
\lim _{n \rightarrow \infty}\left\|y_{n}-T x_{n}\right\|=0, \quad \lim _{n \rightarrow \infty}\left\|z_{n}-x_{n}\right\|=0
$$

Since $\left\{x_{n}\right\}_{n \in \mathbb{N}}$ is bounded, together with (33) we can assume that there exists a subsequence $\left\{x_{n_{i}}\right\}_{i \in \mathbb{N}}$ of $\left\{x_{n}\right\}_{n \in \mathbb{N}}$ such that $x_{n_{i}} \rightarrow y \in F(T)$ (Proposition 12) and

$$
\begin{aligned}
\limsup _{n \rightarrow \infty} & \left\langle x_{n}-z, \nabla g(u)-\nabla g(z)\right\rangle \\
& =\lim _{i \rightarrow \infty}\left\langle x_{n_{i}}-z, \nabla g(u)-\nabla g(z)\right\rangle \\
& =\langle y-z, \nabla g(u)-\nabla g(z)\rangle \leq 0 .
\end{aligned}
$$

We thus conclude

$$
\begin{aligned}
\limsup _{n \rightarrow \infty} & \left\langle z_{n}-z, \nabla g(u)-\nabla g(z)\right\rangle \\
& =\lim _{n \rightarrow \infty} \sup _{n}\left\langle x_{n}-z, \nabla g(u)-\nabla g(z)\right\rangle \leq 0 .
\end{aligned}
$$

The desired result follows from Lemmas 2 and 23 and (98).

Case 2. Suppose there exists a subsequence $\left\{n_{i}\right\}_{i \in \mathbb{N}}$ of $\{n\}_{n \in \mathbb{N}}$ such that

$$
D_{g}\left(z, x_{n_{i}}\right)<D_{g}\left(z, x_{n_{i}+1}\right)
$$

for all $i$ in $\mathbb{N}$. By Lemma 22, there exists a nondecreasing sequence $\left\{m_{k}\right\}_{k \in \mathbb{N}}$ of positive integers such that $m_{k} \rightarrow \infty$,

$$
\begin{aligned}
& D_{g}\left(z, x_{m_{k}}\right)<D_{g}\left(z, x_{m_{k}+1}\right), \\
& D_{g}\left(z, x_{k}\right) \leq D_{g}\left(z, x_{m_{k}+1}\right), \quad \forall k \in \mathbb{N} .
\end{aligned}
$$

This, together with (96), implies that

$$
\begin{gathered}
\beta_{m_{k}}\left(1-\beta_{m_{k}}\right) \rho_{s_{3}}^{*}\left(\left\|\nabla g\left(x_{m_{k}}\right)-\nabla g\left(T x_{m_{k}}\right)\right\|\right) \\
\leq D_{g}\left(z, x_{m_{k}}\right)-D_{g}\left(z, x_{m_{k}+1}\right) \\
\quad+\alpha_{m_{k}} M_{8} \leq \alpha_{m_{k}} M_{8}, \quad \forall k \in \mathbb{N} .
\end{gathered}
$$

Then, by conditions (a) and (c), we get

$$
\lim _{k \rightarrow \infty} \rho_{s_{3}}^{*}\left(\left\|\nabla g\left(x_{m_{k}}\right)-\nabla g\left(T x_{m_{k}}\right)\right\|\right)=0 .
$$

By the same argument, as in Case 1, we arrive at

$$
\begin{aligned}
& \limsup _{k \rightarrow \infty}\left\langle z_{m_{k}}-z, \nabla g(u)-\nabla g(z)\right\rangle \\
& \quad=\lim _{k \rightarrow \infty} \sup _{k \rightarrow \infty}\left\langle x_{m_{k}}-z, \nabla g(u)-\nabla g(z)\right\rangle \leq 0 .
\end{aligned}
$$

It follows from (98) that

$$
\begin{aligned}
D_{g}\left(z, x_{m_{k}+1}\right) \leq & \left(1-\alpha_{m_{k}}\right) D_{g}\left(z, x_{m_{k}}\right) \\
& +\alpha_{m_{k}}\left\langle z_{m_{k}}-z, \nabla g(u)-\nabla g(z)\right\rangle .
\end{aligned}
$$

Since $D_{g}\left(z, x_{m_{k}}\right) \leq D_{g}\left(z, x_{m_{k}+1}\right)$, we have that

$$
\begin{aligned}
\alpha_{m_{k}} D_{g}\left(z, x_{m_{k}}\right) \leq & D_{g}\left(z, x_{m_{k}}\right)-D_{g}\left(z, x_{m_{k}+1}\right) \\
& +\alpha_{m_{k}}\left\langle z_{m_{k}}-z, \nabla g(u)-\nabla g(z)\right\rangle \\
\leq & \alpha_{m_{k}}\left\langle z_{m_{k}}-z, \nabla g(u)-\nabla g(z)\right\rangle
\end{aligned}
$$

In particular, since $\alpha_{m_{k}}>0$, we obtain

$$
D_{g}\left(z, x_{m_{k}}\right) \leq\left\langle z_{m_{k}}-z, \nabla g(u)-\nabla g(z)\right\rangle \text {. }
$$

In view of (112), we deduce that

$$
\lim _{k \rightarrow \infty} D_{g}\left(z, x_{m_{k}}\right)=0
$$

This, together with (113), implies that

$$
\lim _{k \rightarrow \infty} D_{g}\left(z, x_{m_{k}+1}\right)=0 \text {. }
$$

On the other hand, we have $D_{g}\left(z, x_{k}\right) \leq D_{g}\left(z, x_{m_{k}+1}\right)$ for all $k$ in $\mathbb{N}$. This ensures that $x_{k} \rightarrow z$ as $k \rightarrow \infty$ by Lemma 2 .

\section{Conflict of Interests}

The authors declare that there is no conflict of interests regarding the publication of this paper.

\section{Acknowledgment}

This research was partially supported by Grant NSC 102-2115M-110-002-MY2 (Ngai-Ching Wang), and by Grant NSC 1022111-E-037-004-MY3 (Jen-Chin Yao). 


\section{References}

[1] W. R. Mann, "Mean value methods in iteration," Proceedings of the American Mathematical Society, vol. 4, pp. 506-510, 1953.

[2] S. Reich, "Weak convergence theorems for nonexpansive mappings in Banach spaces," Journal of Mathematical Analysis and Applications, vol. 67, no. 2, pp. 274-276, 1979.

[3] Z. Opial, "Weak convergence of the sequence of successive approximations for nonexpansive mappings," Bulletin of the American Mathematical Society, vol. 73, pp. 591-597, 1967.

[4] D. van Dulst, "Equivalent norms and the fixed point property for nonexpansive mappings," The Journal of the London Mathematical Society, vol. 25, no. 1, pp. 139-144, 1982.

[5] J.-P. Gossez and E. Lami Dozo, "Some geometric properties related to the fixed point theory for nonexpansive mappings," Pacific Journal of Mathematics, vol. 40, pp. 565-573, 1972.

[6] G. Chen and M. Teboulle, "Convergence analysis of a proximallike minimization algorithm using Bregman functions," SIAM Journal on Optimization, vol. 3, no. 3, pp. 538-543, 1993.

[7] L. M. Bregman, "The relation method of finding the common point of convex sets and its application to the solution of problems in convex programming," USSR Computational Mathematics and Mathematical Physics, vol. 7, pp. 200-217, 1967.

[8] Y. Censor and A. Lent, "An iterative row-action method for interval convex programming," Journal of Optimization Theory and Applications, vol. 34, no. 3, pp. 321-353, 1981.

[9] F. Kohsaka and W. Takahashi, "Fixed point theorems for a class of nonlinear mappings related to maximal monotone operators in Banach spaces," Archiv der Mathematik, vol. 91, no. 2, pp. 166$177,2008$.

[10] W. Takahashi, N.-C. Wong, and J.-C. Yao, "Fixed point theorems and convergence theorems for generalized nonspreading mappings in Banach spaces," Journal of Fixed Point Theory and Applications, vol. 11, no. 1, pp. 159-183, 2012.

[11] W. Takahashi and G.-E. Kim, "Approximating fixed points of nonexpansive mappings in Banach spaces," Mathematica Japonica, vol. 48, no. 1, pp. 1-9, 1998.

[12] D. Butnariu and A. N. Iusem, Totally Convex Functions for Fixed Points Computation and Infinite Dimensional Optimization, vol. 40, Kluwer Academic, Dordrecht, The Netherlands, 2000.

[13] F. Kohsaka and W. Takahashi, "Proximal point algorithms with Bregman functions in Banach spaces," Journal of Nonlinear and Convex Analysis, vol. 6, no. 3, pp. 505-523, 2005.

[14] C. Zălinescu, Convex Analysis in General Vector Spaces, World Scientific, River Edge, NJ, USA, 2002.

[15] E. Naraghirad and J.-C. Yao, "Bregman weak relatively nonexpansive mappings in Banach spaces," Fixed Point Theory and Applications, p. 2013, article 141, 2013.

[16] Y.-Y. Huang, J.-C. Jeng, T.-Y. Kuo, and C.-C. Hong, "Fixed point and weak convergence theorems for point-dependent $\lambda$ hybrid mappings in Banach spaces," Fixed Point Theory and Applications, vol. 2011, article 105, 2011.

[17] R. T. Rockafellar, "Characterization of the subdifferentials of convex functions," Pacific Journal of Mathematics, vol. 17, pp. 497-510, 1966.

[18] R. T. Rockafellar, "On the maximal monotonicity of subdifferential mappings," Pacific Journal of Mathematics, vol. 33, pp. 209216, 1970 .

[19] D. Butnariu and E. Resmerita, "Bregman distances, totally convex functions, and a method for solving operator equations in Banach spaces," Abstract and Applied Analysis, vol. 2006, Article ID 84919, 39 pages, 2006.
[20] E. Naraghirad, W. Takahashi, and J.-C. Yao, "Generalized retraction and fixed point theorems using Bregman functions in Banach spaces," Journal of Nonlinear and Convex Analysis, vol. 13, no. 1, pp. 141-156, 2012.

[21] S. Reich and S. Sabach, "Existence and approximation of fixed points of Bregman firmly nonexpansive mappings in reflexive Banach spaces," in Fixed-Point Algorithms for Inverse Problems in Science and Engineering, pp. 299-314, Springer, New York, NY, USA, 2010.

[22] W. Takahashi, Nonlinear Functional Analysis, Fixed Point Theory and Its Applications, Yokohama Publishers, Yokohama, Japan, 2000.

[23] N. Hussain, E. Naraghirad, and A. Alotaibi, "Existence of common fixed points using Bregman nonexpansive retracts and Bregman functions in Banach spaces," Fixed Point Theory and Applications, p. 2013, article 113, 2013.

[24] B. Halpern, "Fixed points of nonexpanding maps," Bulletin of the American Mathematical Society, vol. 73, pp. 957-961, 1967.

[25] W. Nilsrakoo and S. Saejung, "Strong convergence theorems by Halpern-Mann iterations for relatively nonexpansive mappings in Banach spaces," Applied Mathematics and Computation, vol. 217, no. 14, pp. 6577-6586, 2011.

[26] T. Suzuki, "Strong convergence of Krasnoselskii and Mann's type sequences for one-parameter nonexpansive semigroups without Bochner integrals," Journal of Mathematical Analysis and Applications, vol. 305, no. 1, pp. 227-239, 2005.

[27] P.-E. Maingé, "Strong convergence of projected subgradient methods for nonsmooth and nonstrictly convex minimization," Set-Valued Analysis, vol. 16, no. 7-8, pp. 899-912, 2008.

[28] H. K. Xu and T. H. Kim, "Convergence of hybrid steepestdescent methods for variational inequalities," Journal of Optimization Theory and Applications, vol. 119, no. 1, pp. 185-201, 2003. 


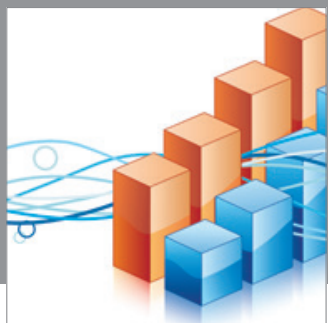

Advances in

Operations Research

mansans

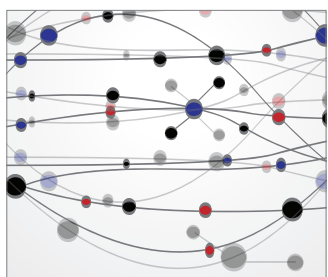

The Scientific World Journal
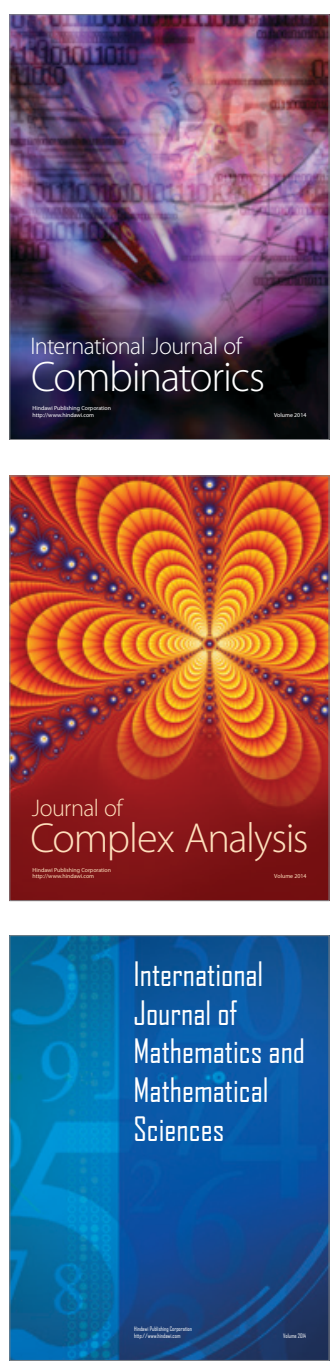
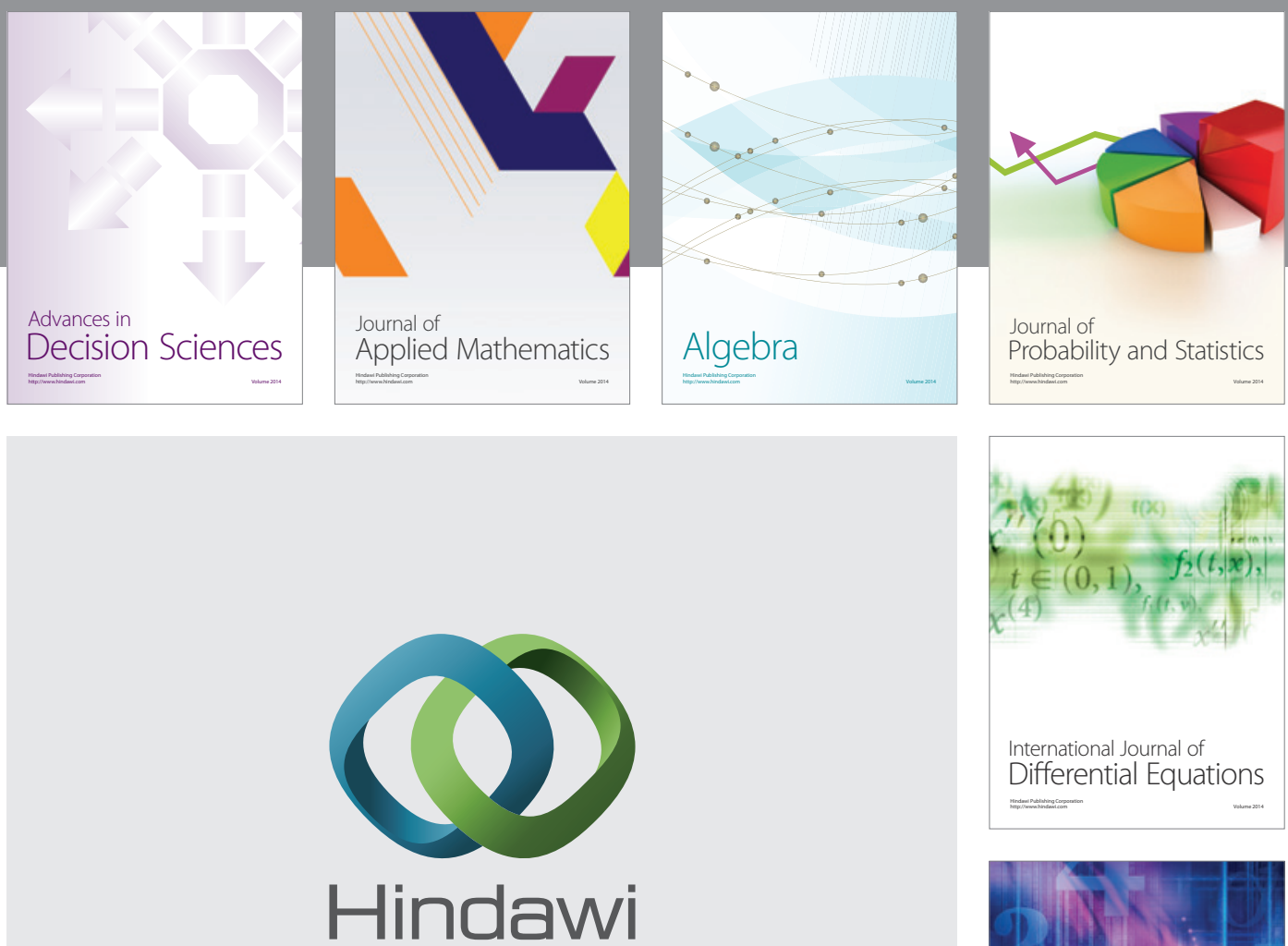

Submit your manuscripts at http://www.hindawi.com
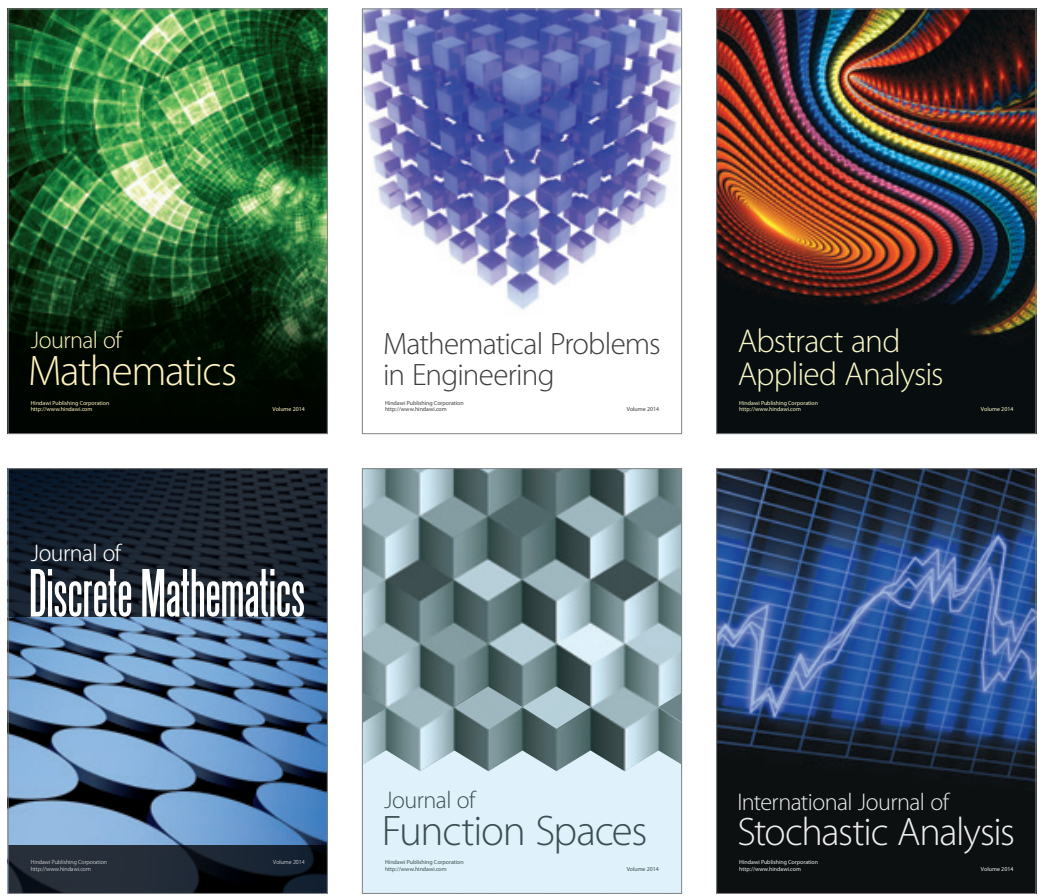

Journal of

Function Spaces

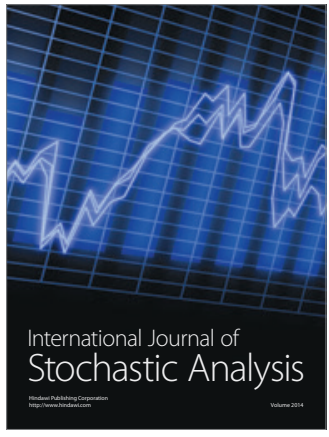


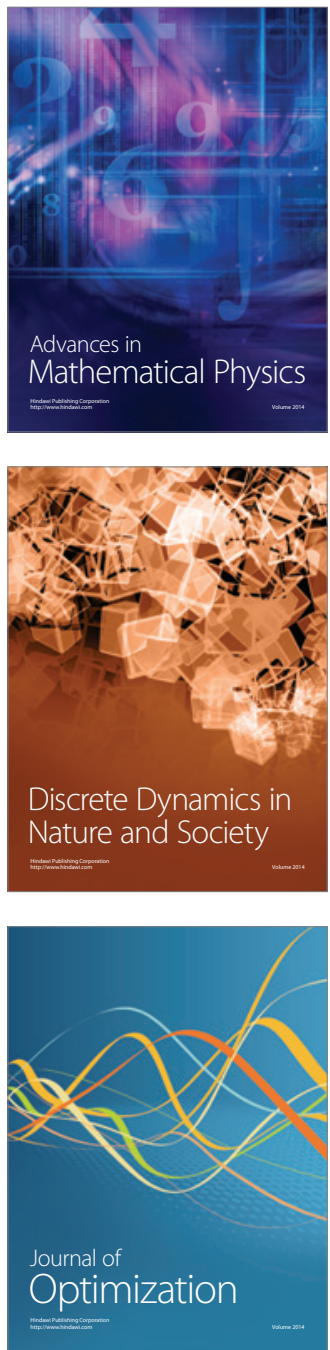